Old Dominion University

ODU Digital Commons

Winter 2001

\title{
Perceptual Cues and Subjective Organization in a Virtual Information Workspace
}

Todd M. Eischeid

Old Dominion University

Follow this and additional works at: https://digitalcommons.odu.edu/psychology_etds

Part of the Databases and Information Systems Commons, Experimental Analysis of Behavior Commons, and the Industrial and Organizational Psychology Commons

\section{Recommended Citation}

Eischeid, Todd M.. "Perceptual Cues and Subjective Organization in a Virtual Information Workspace" (2001). Doctor of Philosophy (PhD), Dissertation, Psychology, Old Dominion University, DOI: 10.25777/ ps9g-zz37

https://digitalcommons.odu.edu/psychology_etds/134

This Dissertation is brought to you for free and open access by the Psychology at ODU Digital Commons. It has been accepted for inclusion in Psychology Theses \& Dissertations by an authorized administrator of ODU Digital Commons. For more information, please contact digitalcommons@odu.edu. 


\title{
PERCEPTUAL CUES AND SUBJECTIVE ORGANIZATION IN A VIRTUAL INFORMATION WORKSPACE
}

by

\author{
Todd M. Eischeid
}

M. S. December 1997, Old Dominion University

A Dissertation Submitted to the Faculty of

Old Dominion University in Partial Fulfillment of the

Requirement for the Degree of

DOCTOR OF PHILOSOPHY

INDUSTRIAL/ORGANIZATIONAL PSYCHOLOGY

OLD DOMINION UNIVERSITY

December 2001

Approved by:

Marl'W/ Scerbo (Director)

Ğlvnh D. Coates (Member)

David f.. Dryer (Memberex)

Thomas W. Mastaglio (Member) 


\author{
ABSTRACT \\ PERCEPTUAL CUES AND SUBJECTIVE ORGANIZATION IN A VIRTUAL \\ INFORMATION WORKSPACE \\ Todd M. Eischeid \\ Old Dominion University, 2001 \\ Director: Dr. Mark W. Scerbo
}

The key to effectively using the immense body of data on the Internet is an efficient method of organizing relevant information. Researchers and designers are beginning to promote the advantages of three-dimensional (3D) models of information storage and retrieval; however, the potential benefits of perceptual depth cues have not been systematically studied.

The present study used a computer task to examine the effectiveness of three types of virtual desktops. A two-dimensional (2D) virtual desktop display, lacking in the cues that give the illusion of depth, was compared to two different 3D virtual desktops, both of which used perceptual cues to convey a sense of depth. One of the 3D desktop conditions conveyed motion parallax through an automatic rotation. It was expected that performance would increase as the number of perceptual cues increased.

The present study also examined the potential benefits of organizing and retrieving documents from a subjectively organized versus a preconstructed, or fixed, information space. An organization that individuals create for their own use may be difficult for others to use. Thus, subjective organization of documents was expected to promote better performance than a fixed organization scheme, which is exactly what the data showed. There was a very strong 
performance benefit to those who organized their own desktops.

Contrary to the other hypothesis, the 2D arrangement was more beneficial to users than either the $3 \mathrm{D}$ or $3 \mathrm{D}$ with motion arrangements. The $2 \mathrm{D}$ advantage may be the result of a number of factors. First, although people live in a 3D world they navigate more on 2D planes. Also, people may naturally encode spatial information in a descriptive or symbolic manner, as opposed to creating a spatial analog in the mind's eye.

Designers should not blindly attempt to create interfaces that mimic the real world. The choice between a 2D and 3D interface should be based upon the type of task to which the interface will be applied. Information storage/recall tasks, including the present task, will most likely benefit from a 2D interface. Other tasks that make greater use of navigation in 3D space may be better suited to 3D displays. 
This dissertation is absolutely dedicated to my wife Amy Westfall Eischeid. She was a champion who guided me through frustrations that inevitably arise when taking on as consuming of an endeavor as a dissertation. I could not have maintained the energy and desire needed to arrive at this puint had she not been the dispeller of bad thoughts and the purger of negativity. Just by being herself, she has helped me everyday to be positive, optimistic, and happy, and I am eternally grateful for her gift. I am a better man for knowing her, and I cannot imagine living without her. 


\section{ACKNOWLEDGMENTS}

I would first like to acknowledge my advisor, Dr. Mark Scerbo, for spending many hours reading and improving drafts of this dissertation. His expertise and attention to detail were invaluable and greatly improved both the quality of this document and the research study itself.

Thanks also go to committee member Dr. Tom Mastaglio, who helped out in the early stages of this work. Our meetings / brainstorming sessions were of great help in channeling my ideas to help develop a sound research study.

I would also like to thank my other committee members, Dr. Glynn Coates and Dr. David Dryer, for their willingness to serve on my dissertation committee. Their time, effort, and comments are greatly appreciated. 


\section{TABLE OF CONTENTS}

Page

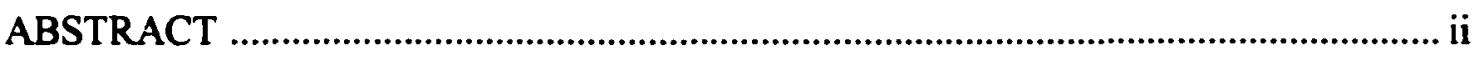

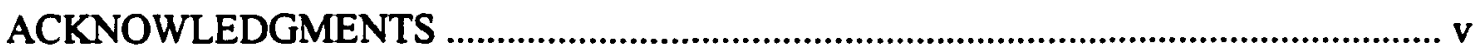

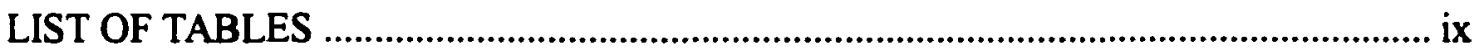

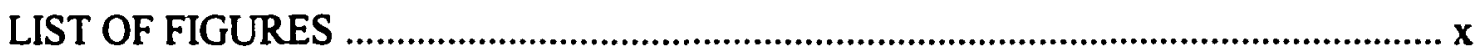

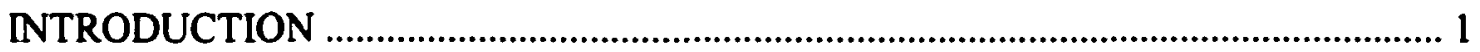

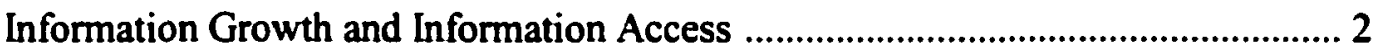

Milestones in Interface Development ................................................................. 3

Command Line / Text Based Interfaces ........................................................ 4

Two-Dimensional Spatial Interfaces …........................................................ 4

Spatial Information Structures ..................................................... 5

Information Workspaces ............................................................. 7

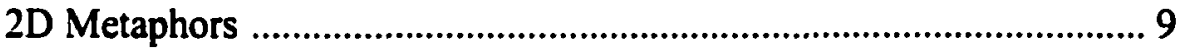

Three-Dimensional Interfaces ............................................................. 10

Perceptual Cues ............................................................................. 10

Performance with Three-Dimensional Displays ................................ 14

3D Metaphors .......................................................................... 16

Conflicting Results Regarding 3D Interfaces ............................................... 18

Subjective Organization of Information Spaces ............................................. 21

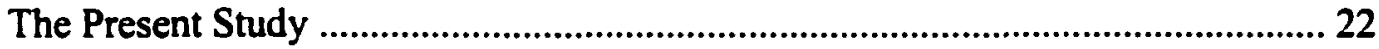

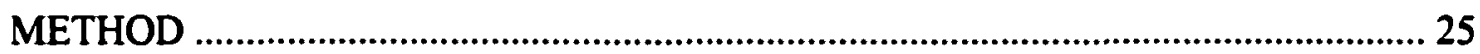

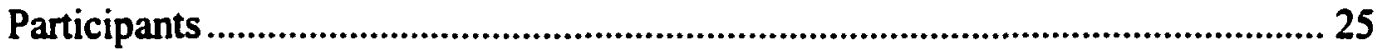

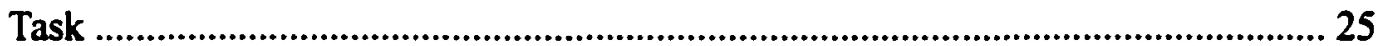

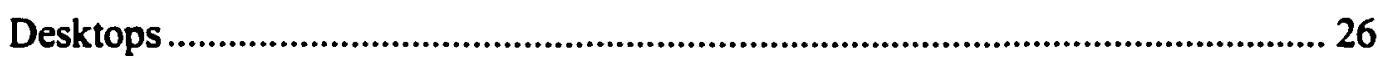

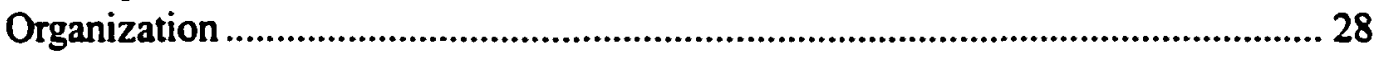

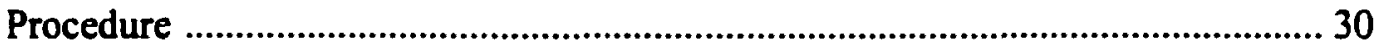

Criteria for Choosing Retrieval Documents .................................................... 33

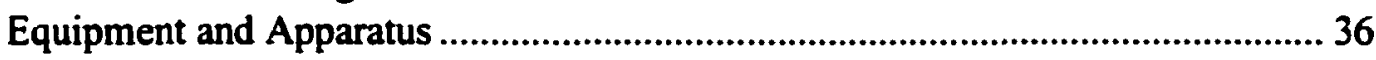

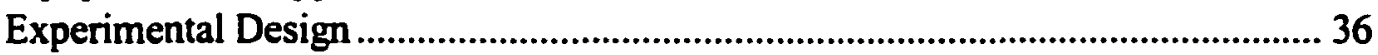

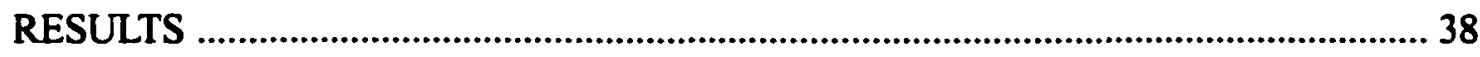

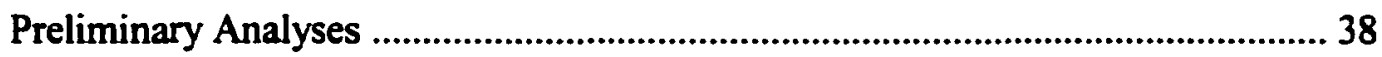

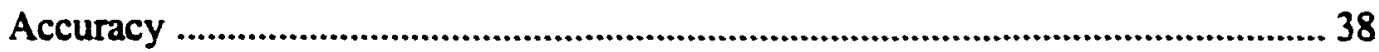

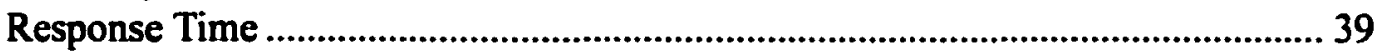

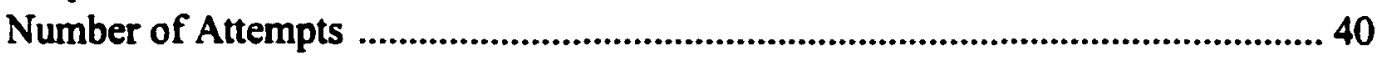

Cluster Analysis and Strength of Categorization Index (SOCI) ........................... 41 


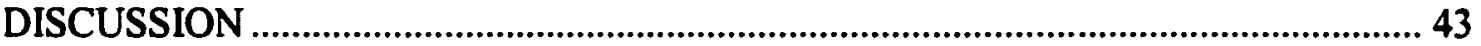

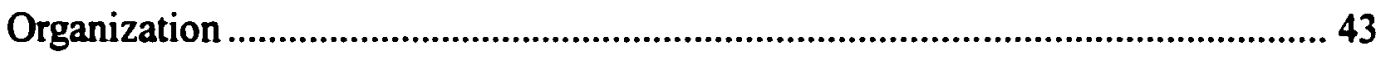

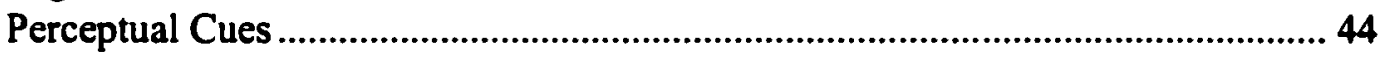

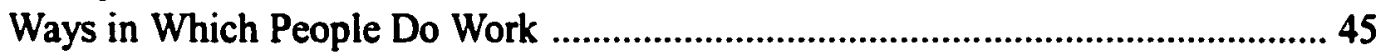

Benefits of Motion Parallax ....................................................................................5 50

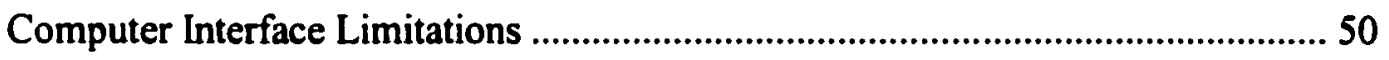

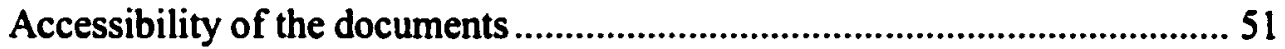

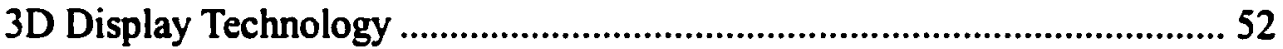

Top Document Visual Cues ................................................................. 54

Perceptual Cues on 2D Desktop ............................................................ 56

Other Predictors of Performance ....................................................................... 56

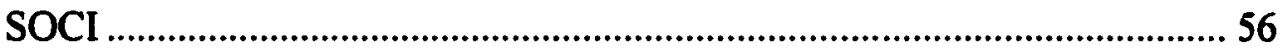

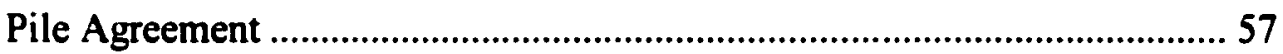

Time On Task During Organization ....................................................... 57

Implications for Design of Information Workspaces ......................................... 57

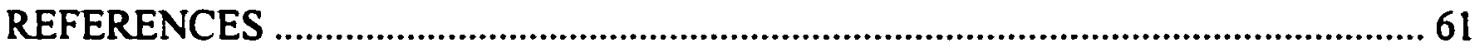

\section{APPENDICES}

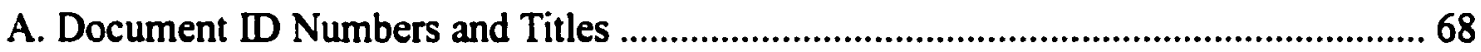

B. Organization Session Instructions, Subjective Condition ..................................... 70

C. Organization Session Instructions, Fixed Condition ................................................ 71

D. Retrieval Session Instructions, Subjective Condition .............................................. 72

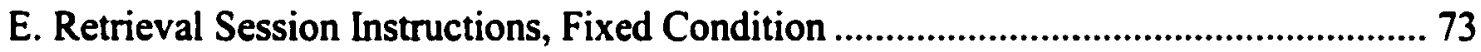

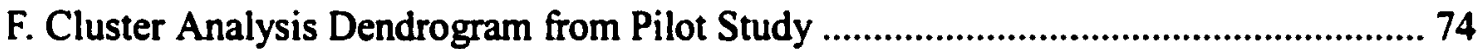

G. Cluster Analysis Dendrogram from Present Study ............................................. 75

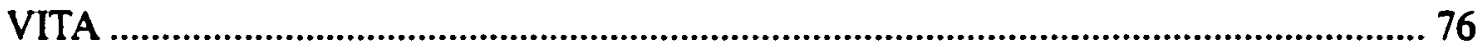




\section{LIST OF TABLES}

Table

Page

1. Source of Variance for Vector Length of First Attempt 38

2. Source of Variance for Response Time for Correct Responses 39

3. Source of Variance for Number of Attempts 41 


\section{LIST OF FIGURES}

Figure

Page

1. Illustration of various depth cues (from Wickens, 1992). ..................................... 12

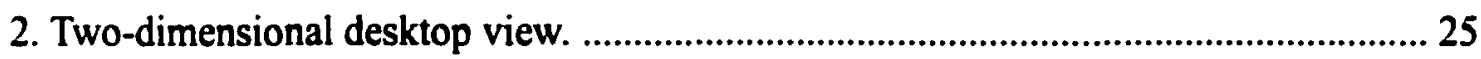

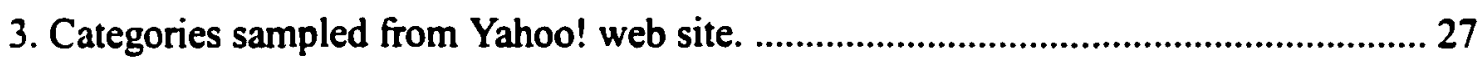

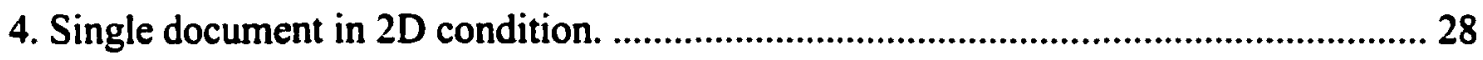

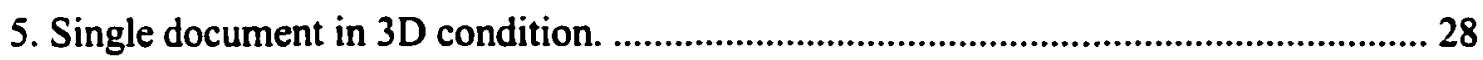

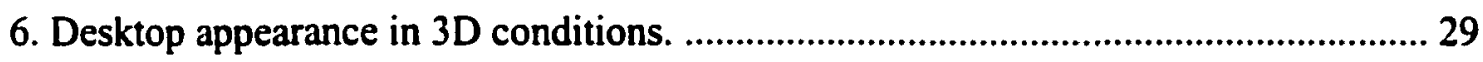

7. Viewing a document on the desktop. ..................................................................... 31

8. Mean vector length for cues as a function of organization. ................................... 40

9. First attempt pile selection as a function of cues................................................46 


\section{INTRODUCTION}

How do people conceptualize the Intemet, also known as the World Wide Web? Is it actually perceived as an incredibly large structure of hyperlinked documents (Mayhew, 1998), or are users only concerned with the small part of the Internet that they interact with during a given session? More importantly, how do users extract, organize, and manage relevant information on the Internet? The answers to these questions have wide-reaching implications for design of the human-computer interface, or rather the human-Internet interface.

Despite the increasingly positive impact of the field of human factors on the usability of software and satisfaction of users, there is little human factors involvement with most materials and information found on the Internet (Forsythe, Grose, \& Ratner, 1998). To exacerbate this situation, Internet use is growing at a rate of about $20 \%$ per month (Foster, 1996), and surely the amount of information growth on the Internet is not much different from that figure.

The number of novice computer users on the Internet is also growing rapidly. This population will need to be able to effectively navigate and locate information on the Internet, and may neither have the time nor motivation to become technically literate in the computer domain or the particular software they are using. The so-called intuitive interfaces of today remain daunting to the technologically naive: the computer desktop metaphor of current computer systems does not map very well to a physical desktop, and users still need substantial technical knowledge of computers in order to effectively accomplish tasks. Perhaps a less restrictive and less technically oriented computer interface would aid users in finding and organizing relevant information, which is currently becoming of great concem (Wickens \& Seidler, 1995).

The model for this dissertation is Human Factors 


\section{Information Growth and Information Access}

Information available to users in all professions around the globe is growing rapidly. Ironically though, physicians and health professionals, for example, are becoming more limited in their ability to locate relevant information on patient care, teaching, and research (Wickens \& Seidler, 1995). In fact, the entire field of "medical informatics" has evolved to specifically manage and organize this massive growth of medical information systems (Hewins, 1990). Users in general are becoming increasingly frustrated because of the difficulties involved in finding and interpreting the specific information they need.

To exacerbate the information growth problem, much of the information being produced lacks a clear structure. In these fluid information domains, organizational structure is not predetermined nor concretely defined. For example, in a fluid type of database, the hierarchies and relationships among items are defined by the needs of the particular user, not by the organization of the database itself (Wickens \& Seidler, 1995).

The Internet is a good example of a fluid domain. There is no predetermined structure for the Internet, and further, the content on the Internet is rapidly increasing, so no formal organization could likely be imposed upon it. This characteristic is an advantage of the Internet, and maintains its flexibility. To bolster this point, Wickens and Seidler (1995) state, “Any effort by one individual to impose a particular parsimonious taxonomy will probably defeat other users with different needs and information uses" (p. 207).

While formal organization of a domain such as the Internet would be an unwieldy and futile task, a loose structure could be created for each individual user as he or she navigates through numerous Internet pages and sites. A study by Abrhams (1997) showed that users of the Intemet often use some type of bookmarking mechanism, provided by current web 
browsers, to store the locations of often visited or personally important web sites. In doing so, users were actually creating personal web information spaces, small and personally relevant views of the Internet, in an attempt to deal with the overwhelming amount of both relevant and irrelevant information, and the constantly changing appearance of the Internet.

An optimal information structure would help the individual user visualize, organize, and retrieve the information they find, and prevent them from having to maintain this structure in their own working memory. Given current technology, the human-computer interface for this task could be (a) text-based, as are most current mechanisms such as bookmarks in web browsers; (b) graphically-based, with icons and text labels in two-dimensional (2D) space such as the Microsoft Windows desktop; or even (c) graphically-based in three-dimensional (3D) space, in which the user manipulates 3D objects such as books or folders, and navigates different rooms, buildings, or landscapes to help them store and retrieve information. Threedimensional interfaces may be of benefit to users since we live in a natural 3D environment and have much practice manipulating 3D objects.

\section{Milestones in Interface Development}

Human-computer interfaces in general, have evolved from simple character displays to ones that mimic real world tasks and virtual objects in space and allow the user to manipulate objects directly just as they would in the real world. Some examples used in personal computers include the Xerox Star (Smith, 1981), Unix Motif, Apple Macintosh, and the omnipresent Microsoft Windows. Generally referred to as direct manipulation interfaces (DMI), these interfaces capitalize on peoples' experiences manipulating their environment and the objects within it (Hutchins, Hollan, \& Norman, 1985; Jacob, 1989). Virtual environments are even more direct and realistic as the user is immersed in a 3D virtual world. Enabling 
human-computer interaction with representations of real world objects presumably promotes better mental models and helps the user to accurately predict solutions to novel situations. Users bring to the computer interaction cognitive models based on real world concepts, especially spatial concepts (Cole, 1982).

\section{Command Line / Text Based Interfaces}

The earliest computer displays were only capable of displaying alphanumeric characters in a single color. The user instructed the computer to do various tasks usually by typing in some sort of command, which was often an abstract or arbitrary pseudo-word (Schneiderman 1998). In the 1980's, for example, text editing was performed by viewing a single line of text on the screen. Actions such as deleting or inserting words, required the use of single key or chorded commands consisting of sometimes arbitrary, irreversible sequences.

\section{Two-Dimensional Spatial Interfaces}

Most popular interfaces today use a 2D spatial representation, which has all but replaced text based computer interfaces. These current display editors use a spatial metaphor and a wysiwyg (What You See Is What You Get) approach. Text manipulation in these systems is performed by directly "touching" the text on the screen with a pointer (usually controlled by a mouse) and by selecting pictorial buttons or icons that perform desired actions. In addition to their strong visual appeal, research has shown improved performance and reduced training times for display editors (Schneiderman, 1998).

The advantage of direct manipulation interfaces over command-languages and textbased interfaces, however, is task specific. In some situations, for example, markup languages and macro languages offer greater flexibility than could be achieved through a graphical direct manipulation approach. Peters, Yastrop, and Boehm-Davis (1988) illustrated this point in a 
study comparing performance on graphic and alphanumeric representations of an airline reservation database. Questions involving spatial relationships, such as how to get from one point to another, were better answered using a graphic layout, while questions involving more verbal concepts, such as how many flights arrive at a particular time, were better answered with an alphanumeric layout. Thus, research is not likely to reveal an absolute advantage of spatial over alphanumeric interfaces or vice-versa. Indeed, any benefit of spatially oriented interfaces will have to be considered in the context of the user's task.

The spatial characteristic of direct manipulation interfaces is not always a benefit to the user. Indeed, much research has shown that users can get disoriented in these types of systems, unable to return to specific spatial locations (Billingsley, 1982; Vicente, Hayes, \& Williges, 1987; Wickens, 1992; Woods, Roth, Stubler, \& Mumaw, 1990). Some factors that can lower performance are (a) abstracted methods of interacting with objects in the display, (b) inability to predict computer behavior in novel situations, and (c) a lack of fidelity in the interface.

\section{Spatial Information Structures}

An important advantage of 2D interfaces over command line interfaces is that they leverage human spatial memory to aid users in interacting with the computer. Using spatial processes to organize information such as thoughts or ideas is by no means novel. In fact, the concept dates back to around 86 B.C. with the Method of Loci (Yates, 1966; in a work commonly known as Ad Herennium, written by an unknown teacher of thetoric in Rome). This method is a mnemonic whereby places and images are associated in memory, and was originally used by orators to help them remember long speeches. A place, or locus, is that which can be easily visualized in memory, such as a particular house, a comer of a building, or an archway. Architectural images were most commonly used. Images are the forms, marks, or simulacra of what one wishes to 
remember. For example, an image could be a book or the genus of a lion. Thus, the image and place in each pairing need not have a readily identifiable relation to one another and usually do not. To later recall the book or lion, these images are placed on specific loci in one's mind. The sequence of image-loci pairings is important since a speech or some other temporally based item is the target of recall. For example, an orator may imagine himself or herself walking through a familiar building. As each room is mentally encountered (the locus), the orator places an image into the room (book, painting) that will help him or her remember a particular passage from the speech. Upon mentally encountering the next room, another image may be used to help remember the next part of the speech. While giving the speech, the orator would mentally walk through that familiar building with the same route, encounter the image at each locus, and thus be reminded of the subject of a passage or section of the speech. Obviously, this method relies heavily on spatial memory, and has been quite an effective tool throughout the ages.

One argument for using a spatial means of organizing information is the apparent incidental or unconscious storage of location information (Jones \& Dumais, 1986; Mandler, Seegmiller, \& Day, 1977). Further, encoding this information is relatively effortless, meaning it does not draw upon mental resources being used to encode other information about an object, such as a name. For example, in a task requiring the storage and retrieval of objects in space, Mandler et al. (1977) asked participants to remember information about 16 different toys placed at various points in a $6 \times 6$ array. Half were instructed to remember only the toy name, and the other half were instructed to remember both the name and location of the toy. Upon recall, all participants were asked to recall both the name of toy and the location of the toy. Surprisingly, the performance of those instructed to remember both names and locations 
was only marginally better than that of those who recalled just the toys. Thus, even when not instructed to do so, participants remembered the locations of the toys, which did not interfere with performance of remembering the toy itself: an incidental learning of location of the stimuli.

Within an office environment, Cole (1982) found that workers rely heavily on their spatial memory for everyday tasks. The physical location of a particular piece of information in the office environment, for example, proved more important than a categorical means of representation, such as a filing system. Cole further stated that this spatial type of organization compensated for the lack of a categorical filing system and actually prevented the office workers from having to refer to paper-based indexes. Many workers initially organized their filed items into a system of indexes and color-coding schemes but did not expend the mental resources over time required for filing and organizing incoming information into such a formal system. Rather, they resorted to a more spatial strategy that did not require much organizational decision making with incoming information, such as memos and reports. This type of behavior is important because it shows that if given a choice, people may circumvent more categorical means of representation in favor of a spatial strategy, even if the physical location of the piece of information is not relevant to its content. Mandler et al. (1977) might argue that the workers encoded location information in an unconscious and effortless manner, allowing them to more easily find it later. Thus, a spatial scheme for organizing information may be quite natural for humans.

\section{Information Workspaces}

The arena in which users access and work with information has been termed an information workspace (Card, Robertson, \& Mackinlay, 1991). Essentially, an information 
workspace is a virtual or physical environment in which users compare, manipulate, and store information of personal interest. Examples are a secretary's physical desktop, 2D iconic computer desktops, such as the Microsoft Windows desktop, and bookmarks/hotlists in web browsers. Each piece of information in a user's physical information workspace (for example, phone lists, folders in filing cabinets, and papers on a desk) has a cost associated with accessing it. Frequently used information might be kept where the access cost will be low, while the less frequently used information may be kept in a filing cabinet where the cost is higher. This same principle can presumably be applied to virtual information workspaces such as a filing system on a computer.

In addition to the cost of information access, there is also a cost of information organization. Card et al. (1991) failed to mention this critical first step: before users can access their information, they must actually organize it in some manner. Thus, while a hierarchy can allow access to greater amounts of information relative to the access cost, there is much evidence that users do not expend the time or energy required for such organization. This is especially true for new and unfamiliar information, which users have great difficulty categorizing (Mander, Solomon, \& Wong, 1992). Unfortunately, most current graphical computer environments offer the user only a hierarchical filing system for managing all of their information, and users typically have difficulty organizing and later retrieving information from hierarchical file systems (Fertig, Freeman, \& Gelemter, 1996). As noted previously, studies of physical office environments have shown that users group items spatially and often work with piles of papers as opposed to more formal categorical organization methods (Lucas \& Schnieder, 1994; Malone, 1983; Mander et al., 1992). Again, this suggests that the lowest cost of information access might be achieved with a spatial as 
opposed to a categorical scheme.

Some studies have revealed that creating spatial arrangements of documents, or "piles", is the primary means by which people organize their workspaces. For example, Mander et al. (1992) discuss how users tend to organize information in highly personalized piles on their office desks. Piles provide an informal, fast method of organizing incoming information, and many users create numerous piles representing various topic areas. Even a document's relative location within a pile can convey information to the user such as its age or priority. Lucas and Schneider (1994) found that piles were used extensively for short-term storage and organization of documents. The physical location of a document was a powerful retrieval cue in that study. A quote from one of the participants bolsters this point: "Where it is, is what it is". Mander et al. (1992) used a 2D computer interface that extended real world functionality and helped users to organize information into piles. Items such as computer files, represented as documents, could be placed into piles.

\section{D Metaphors}

Metaphors are often used in 2D interfaces to aid the user in operating the interface. Multitudes of metaphors have been used in human-computer interfaces in various contexts, including information spaces, multimedia, group work, and virtual reality (Neale \& Caroll, 1997). The metaphors that will be discussed here apply mainly to information spaces, the most popular perhaps being the $2 \mathrm{D}$ desktop metaphor.

A desktop is an extremely familiar concept to those working in office settings and manipulating documents and file folders on a desktop is a common task for many people. As such, the metaphor of a desktop should be a good candidate for a human-computer interface. The use of a physical desktop metaphor in an interface was first accomplished commercially by 
the Xerox Corporation with the 8010 Star Workstation, and later in the Apple Macintosh and Microsoft Windows systems. Although the early Xerox system was highly abstracted from the appearance and behavior of a physical desktop, users had a familiar context in which to accomplish tasks. The desktop metaphor implemented later in the Apple Macintosh and Microsoft Windows is more visually appealing and functional than its predecessor, but all of these desktops are 2D interfaces displayed on a flat screen. In other words, they are inherently spatial, but lack the richness and visual depth cues found in the real world.

\section{Three-Dimensional Interfaces}

Recently, computer interface designers have taken advantage of numerous visual cues to create a sense of depth in 2D computer displays. This illusion of depth is the distinguishing characteristic between $2 \mathrm{D}$ and $3 \mathrm{D}$ displays. The rationale behind these $3 \mathrm{D}$ perspective displays is that they can offer more natural modes of interaction, since humans have extensive practice interacting with and manipulating objects in three dimensions. Greater information density can also be achieved using 3D, as opposed to 2D space (see Robertson, Czerwinski, Larson, Robbins, Thiel, and van Dantzich; 1998). Further, humans expend almost no effort perceiving 3D space, so access to added information in a higher density display comes at little cost.

\section{Perceptual Cues}

There are numerous visual cues that distinguish 2D and 3D space. Those contained within the visual scene itself, and independent of the observer's location and visual system, are termed object-centered, or pictorial cues. Many of these are illustrated in Figure 1. One pictorial cue is linear perspective. For example, when two lines seem to converge near the horizon, we perceive these lines to be parallel lines that are receding in depth. The edges of 
the road in Figure 1 illustrate this cue. Another cue, height in plane, refers to the tendency to perceive objects that are higher in our visual field as being more distant. Vehicle $\mathrm{A}$ in Figure 1 is higher in the image than Vehicle B, so we perceive it to be farther away. Occlusion is another important depth cue. When the lines and contours of a given object hide or occlude those of another, we perceive the occluded object to be further away. Notice that the contours of building D in Figure 1 obscure slightly those of building $C$. Another cue concerns the visual angle of an object. When two objects are assumed to be the same size, and one object subtends a smaller visual angle on the retina, the smaller object is assumed to be at a greater distance. This cue is known as relative size. We assume that the two vehicles in Figure $l$ are the same size, but because vehicle A subtends a smaller visual angle than vehicle $B$, we perceive it to be farther away. Light and shadow cues are also useful when a single, common light source shines on a scene, lighting selected surfaces of objects and casting shadows. This conveys information regarding an object's shape, volume, and relative position. Textural gradients, a cue described by Gibson (1950), are actually a combination of linear perspective cues and relative size cues. Texture can be any collection of objects in the visual field (Caelli, 1982). When there is a reduction in size and an increase in the number and compactness of elements in the gradient, we perceive those elements to be receding into the distance. The rows of com in the left hand portion of Figure 1 illustrate this cue.

Unlike the perceptual cues discussed above, which can characterize static images such as photographs, motion parallax can only be achieved through movement of the observer. Assume the observer is facing an object in his visual scene, such as a tree, and is also fixated on it. If the observer turns and moves laterally, while remaining fixated on the original object, all objects in front of the fixation point will appear to move in the opposite direction of the 


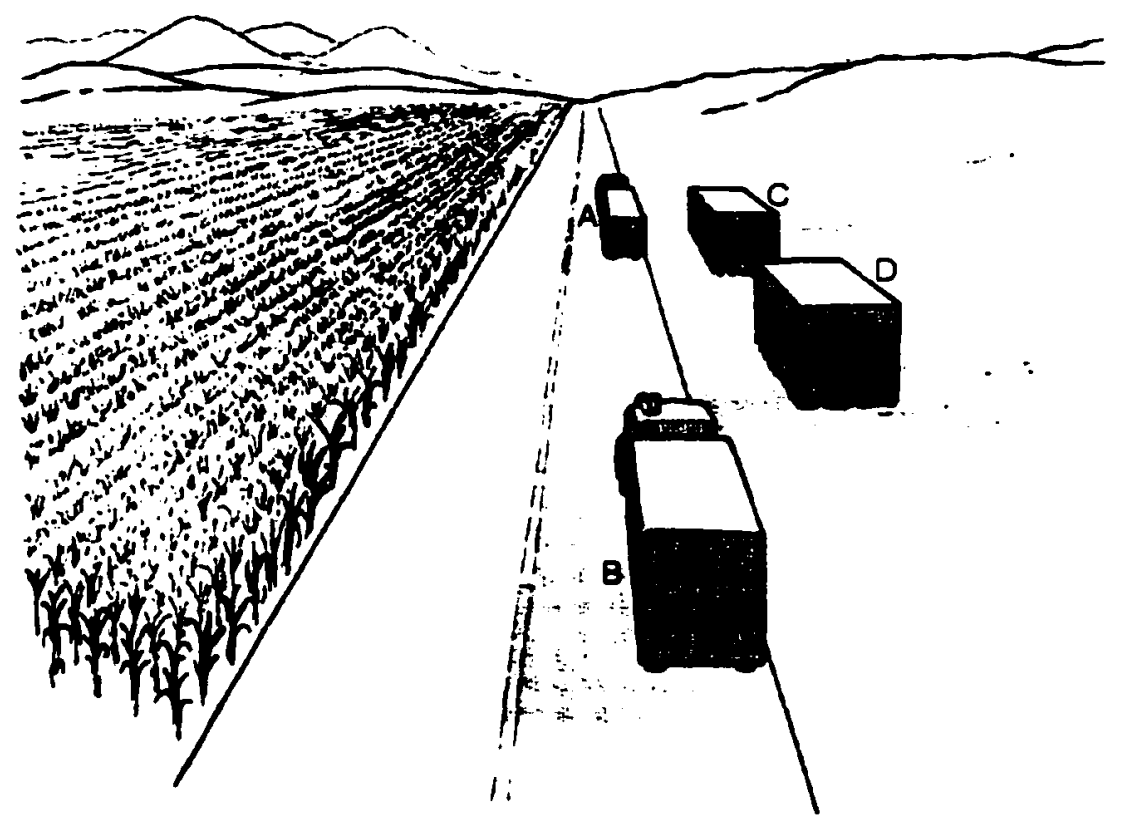

Figure 1. Illustration of various depth cues (from Wickens, 1992).

observer, while all objects behind the fixation point will appear to be moving in the same direction as the observer. Further, the optic flow (how fast objects are moving across the visual scene) in front of and behind the fixation point varies as a function of distance from the retina.

A continually changing viewpoint, or optic flow, across the retina conveys much depth information inaccessible to the static observer. Consider a CAT scanner, the medical instrument used for brain imaging (Regan, Kaufman, \& Lincoln, 1986). Multiple X-rays of the brain from different angles provide information unobtainable from a single $\mathrm{X}$-ray of the brain. The effectiveness of the CAT scanner comes from its ability to obtain information from multiple viewpoints and then very quickly extrapolate to form a whole picture of the brain. The result gives the human observer rich and readily understandable information. The brain also uses processes similar to the CAT scanner in that it combines information from the 
continually changing viewpoints of a scene or object into a more coherent whole than could be obtained from a single, static viewpoint. It has been shown that depth perception can be generated by motion parallax (Graham \& Rogers, 1982; Rogers \& Graham, 1982). Also, objects that are camouflaged and difficult to detect can be made visible through motion parallax by simply having the observer move. Further, it has been shown that different visual processes are used under these conditions than those used to detect noncamouflaged objects (Anstis, 1970; Braddick, 1974; Foster, 1971; Poggio, Reichardt, \& Hausen, 1983; Regen \& Spekreijse, 1970; Reichardt \& Poggio, 1979). This suggests that a more complete view of a scene can be created when relative motion is introduced.

By contrast, the kinetic depth effect occurs when the observer is stationary, but objects themselves move or rotate. Specifically, when an object such as a cube is rotated, its projection to the viewer undergoes a continuous, cyclical transformation. The relative movement patterns of the different parts of the cube convey information about its 3D shape. This can resolve size and shape ambiguities that sometimes occur in static scenes. Even when the transforming projection could be perceived as a two-dimensional image changing shape, there is a very strong tendency to perceive the transformation as a 3D object that is rotating in depth (see Braunstein, 1962, 1976; and Ullman, 1979 for a review of this research). For example, a 2D circle transforming into a diagonal line is most often perceived to be a circle that is rotating in depth (Philip \& Fisichelli, 1945; Weber, 1930).

The kinetic depth effect can produce quite accurate estimations of the projection in depth of a particular object and also objects' relative positions to one another. For example, White and Mueser (1960) used shadows of vertical pegs rotating on a turntable and designed the experiment to eliminate changes in contour length and orientation. Even so, observers 
perceived the shadows as objects projected in depth and accurately described the placement of the pegs on the turntable. Collectively, the findings from studies such as these suggest that the perception of depth in 2D displays can be enhanced through dynamic changes in information presentation.

\section{Performance with Three-Dimensional Displays}

There are many situations in which a 3D display can boost performance and decrease the likelihood of errors. Specifically, the greater the match between the display and the user's mental model of the data represented, the less effort needed to interpret the display. For instance, flight control and predictions of flight paths benefit greatly when a properly constructed 3D display of the airspace is used to represent aircraft in flight, as opposed to one or more 2D displays. The concept of a flight path implies 3D space, and the user's mental model is probably similar, so it would seem intuitive that a 3D display would be beneficial to the user.

Accordingly, it is possible that 3D piles on a desktop may fit the user's mental model of how to store web documents for later retrieval, more so than an abstracted 2D desktop or an alphabetized or categorized list of titles of web documents. For example, a document metaphor has been used since the earliest web browsers and users have presumably perceived the content in a web browser as various documents. It follows, therefore, that a realistic 3D desktop would most closely fit the user's perception of web content.

Researchers have begun to examine various 3D interfaces for structuring the myriad information on the Internet and in the workplace. Robertson et al. (1998) studied how users manage Internet-style documents. They compared a spatially oriented, 3D representation termed "Data Mountain" with the Microsoft Internet Explorer "Favorites" mechanism. The 
Data Mountain displays an inclined surface on which users place various documents. Each document is represented individually on the surface and no document piles or folders can be created. Users can drag documents around the surface to arrange them however they wish. The results showed better organization and retrieval performance for documents with the spatial Data Mountain display as opposed to the text-based display used by "Favorites". Specifically, Data Mountain enabled reliably faster and more accurate retrieval of web pages when participants were asked to locate a particular page that they had organized.

Although there is intuitive appeal for 3D user interfaces, there is a fair degree of abstraction from the real world to a representation of that world within an information display. For example, the quality of the visual display is always less than that of the real world. Limitations of computing power can cause degradations in the motion and texture of objects. As such, a poorly designed 3D interface can make information more difficult to locate and the cognitive load on the user may be greater due to the abstract or arbitrary methods of navigating in each added degree of freedom (i.e., specific keyboard keys, mouse moves or clicks). This is especially true when the virtual information space is unfamiliar to the user. Careful design of 3D interfaces can help avoid these problems.

With certain types of tasks, displays of 3D space can result in faulty perceptions. Specifically, when precise absolute or relative judgements must be made from a 3D display, such as comparing data in a 3D graph with data points at varying depths, the likelihood of incorrect estimations increases. Misjudgments of size and depth are particularly likely when 3D space is presented on a 2D flat panel display (Gregory, 1977). Unfortunately, these processes are rather automatic and are not easy to alter through conscious effort and/or training (Wickens, 1992). In sum, 3D displays can benefit performance in many tasks and 
hinder performance in others; thus, the type of display used must be considered in light of the task at hand.

One type of 3D interface that is gaining popularity is the virtual world or virtual environment (VE). Virtual environments differ from flat-panel perspective displays in a number of important ways. First, in a true virtual environment, the user is immersed in the interface. Second, virtual environments convey a sense of presence to the user, or the subjective experience of being in one place when one is physically in another (Witmer \& Singer, 1994). Last, virtual environments allow users to interact with objects in the scene. In true virtual environments, users can walk through buildings, pick up virtual objects in a similar manner to how they would pick up a real world objects, and generally interact with the world using more familiar, natural methods.

\section{D Metaphors}

As in 2D interfaces, metaphors are also used extensively in the 3D environment. Utilizing appropriate visual cues, the 2D desktop metaphor could also be expanded into a 3D desktop to create a more realistic and perhaps more useful information space. This "deskscape" could offer the user a simple and effective method of spatially structuring information much as they would on a physical desktop. Visual depth cues would allow items to be placed at varying distances and higher information density could be achieved than with a 2D desktop interface.

A metaphor such as a city, in which city blocks, streets, buildings, etc. can also represent various levels and forms of information, could also be used to represent an information space. Lynch (1960) explored peoples' concept of the urban landscape, which he termed the "image of the city". Each person's image of his or her urban environment is likely to be quite 
personal and individualistic. Some objects that have little physical uniqueness may nonetheless be important to an individual's image because of high familiarity (i.e., a building passed on the way to work everyday). Other objects may have importance because of a preexisting stereotype. For example, the comer drugstore may be a familiar sight to people in the urban city. Lynch suggests five major elements that comprise a city: paths, edges, districts, nodes, and landmarks. Thus, the 3D cityscape can offer a familiar, extensible, and rich method of creating web information spaces. Numerous studies have explored the cityscape as a metaphor for a user interface (Darken \& Sibert, 1996; Elvins, Nadeau, Schul, \& Kirsh, 1998; Witmer, Bailey, Knerr, \& Parsons, 1996). However, those studies have mainly been concerned with egocentric wayfinding and participants' ability to navigate from one point to another within a virtual environment.

A number of other metaphors have been used in the context of information structures. The Storehouse/Room metaphor (Pejtersen \& Nielsen, 1991; Vaananen, 1993) uses a house and room structure to organize and present different categories of information. For example, Pejtersen and Nielsen (1991) used various "rooms" in a storehouse for works of fiction in a library. Vaananen (1993) also used a library metaphor containing different sections, bookshelves, and books. Landscape metaphors have also been used (Shafrir \& Nabkel, 1994) for large information structures. Users draw upon their knowledge of mountains, lakes, roads, and maps to traverse the information space. Space metaphors can aid users even when no visual presentation of a specific space is used. For example, the commands used in current web browsers, such as Back, Forward, Jump, Go to, Address, imply direction or location in space. However, no such space is explicitly presented within the web browser. Some spatial metaphors on the Internet do however present explicit visual spaces to the user. There is a 
"travel" metaphor (Hammond \& Allinson, 1987), in which information is structured as places that the user can visit. Users can traverse the information space using guided tours, independent travel, and maps. Pile metaphors (i.e., Lucas \& Schneider, 1994; Mander et al., 1992), allow users to create piles of documents rather than the traditional file folders found on many computer operating systems. The "Bags and Viewers" metaphor allows the user to create bags to hold information, and then later browse each bag using various filters (Inder \& Stader, 1994).

\section{Conflicting Results Regarding 3D Interfaces}

There are conflicting views in the literature regarding the benefits of organizing data via 3D user interfaces. A 3D interface possesses face validity as it more closely matches the way in which we interact with our environment. Further, as noted above, a number of studies have demonstrated a tendency for humans to conceptualize and organize information in their environment in a spatial, 3D manner. Others, however, have shown a greater advantage for organizing information in a textual manner.

One reason for the conflict is a general failure to properly test the parameters for which benefits to the user are stated. For example, Robertson et al. (1998) found a benefit for their 3D model of data organization, but the conditions tested may not have permitted a valid comparison. They compared a nonspatial, textual format (the Microsoft Internet Explorer 4 "Favorites" mechanism), to a 3D spatial format which they termed "Data Mountain". Thus, it is not possible to isolate the exact source of the benefit since the two conditions differ on many parameters.

In another example, Elvins et al. (1998) tested the effectiveness of 3D "worldlets" that allow users to explore small snapshots of a 3 block by 3 block virtual city. A worldlet 
displays interactive landmarks, such as a gas station or a storefront, in 3D space. The user can manipulate the scene for a given landmark by changing viewpoints. Participants were required to navigate to various landmarks and ultimately to a virtual goal kiosk using one of three methods: (a) reading text, (b) viewing flat images (thumbnails) of perspective views of city-like landmarks, or (c) using an interactive worldlet that allowed the participant to change viewpoints of the landmark. Curiously, the authors proposed that they were comparing $2 \mathrm{D}$ (thumbnail images) and 3D (worldlets) methods of navigating to various landmarks in a virtual city. Although the thumbnail images were presented in two dimensions, those images portrayed perspective views and conveyed much $3 \mathrm{D}$ information. It is misleading to call the thumbnail image condition a $2 \mathrm{D}$ condition. Thus, there is a confound in comparing the thumbnail image condition with the worldlet condition.

The results of Jones and Dumais (1986) showed benefits for referring to objects by descriptive name rather than by spatial location. In that study, users were better able to locate articles they had read if they previously stored the articles using a naming scheme as opposed to spatial 2D and 3D methods. Even when participants were able to store their information by spatial location in an actual office, as many workers do, a name-only scheme proved superior by comparison. If this is indeed representative of office behavior, then why do people tend to organize their offices in a spatial manner as opposed to naming and labeling items and simply filing them? Is the reason simply because the cost of organizing information in a spatial manner is lower and humans will tend to engage in the lowest cost actions? These questions were not addressed in that study. The Jones and Dumais (1986) results are also difficult to interpret with regard to the exact source of benefit to the user, since two- and three-letter text labels were compared to more spatial organization methods. 
Another reason why Jones and Dumais (1986) may not have found benefits for spatial location may lie with their dependent measure. They measured only the accuracy of participant responses using a dichotomous measure and did not impose a time limit; thus, all participants had ample time to arrive at a correct response, which could have potentially influenced the results. The researchers did mention the possibility that spatial information might help users "home in" on an object more "quickly", indicating that a response time measure might have been more sensitive to the effects of spatial organization.

Westerman (1998) compared target search performance with 2D and 3D visualizations of a database. Although there were characteristics of the 3D layout that would seem to offer an advantage to users, no performance benefit was found in the 3D condition. Specifically, the conditions did not produce differences in response times or implicit learning. This is surprising considering that the distance to the targets was less in the $3 \mathrm{D}$ than the $2 \mathrm{D}$ condition. Even more surprising is that participants' subjective reports showed they believed they expended greater effort to accomplish their tasks in the 3D layout. It is unclear, however, what effects the fidelity of the interfaces had on performance and perceived effort.

Park and Woldstad (2000) tested the difference between performance with a 3D flat panel display versus multiple 2D flat panel displays using a virtual telerobotic task. The multiple 2D display condition was comprised of 4 separate views: a bird's eye, or plan view, right-side view, left-side view, and front view. The 3D display condition used a single view display of a 3D scene. Participants were required to pick up a virtual object and put it into a storage rack within the scene. On a series of measures such as time to completion, robotic arm distance traveled, and number of errors, the multiple 2D displays proved to be slightly better. However, even a cursory examination of the $2 \mathrm{D}$ views used shows that even though 
they are not perspective views, much depth information, such as light/shadows and occlusion, is present. In sum, no conclusion can be drawn from this study regarding the effects of perceptual cues on performance since the conditions somewhat confound this issue.

The examples above illustrate the difficulty in determining specific characteristics of an information display that may have benefited users in past studies. It is not clear whether users benefited from the spatial nature of the displays or more specifically, from the three dimensional characteristics.

\section{Subjective Organization of Information Spaces}

Most current users of the Internet and other information presentations are required to interact with information that has been organized by someone else, such as a web site designer. The method by which a designer structures a web site may not fit the goals of the user or the user may not fit the target audience of the particular site. This lack of fit makes the user's task of finding desired information more difficult. Robertson et al. (1998) examined the effects of an unrestricted spatial arrangement of objects on retrieval of information in a virtual environment. In other words, users had complete freedom to organize the relevant information in their spaces. This element of user control resulted in highly personalized information spaces and provided a more effective way for users to interact with the information space. Accordingly, one could argue that users should have more control over the construction of their own information spaces.

The literature has not systematically examined the effects of subjective organization of information spaces. Consequently, many research questions have not been addressed. For instance, how does the ability to interact with and navigate an information space constructed by someone else differ from one organized by the user? Should the user ultimately be able to 
create his or her own representations of the web sites they encounter to best help them store and retrieve personally relevant information?

As noted previously, Mander et al. (1992) used the metaphor of document piles as a method of storing and retrieving information. They discussed the subjective and personal nature of piles of information for each user. In other words, the organization scheme that one user creates for items within and across piles may not work quite well for another user. Moreover, one user's method of organization may even appear disorganized to another. However, their field study examining user retrieval of information from 3D piles on a 2D desktop focused was on ways of visualizing the contents of a pile. Thus, they did not systematically examine the effects of subjective organization of information.

\section{The Present Study}

Although researchers and designers are beginning to promote advantages for 3D models of information storage and retrieval, the potential benefits of specific perceptual depth cues have not been studied in any systematic manner. Also, it is not known whether the effectiveness of the interface increases as the number of perceptual cues increases. For example, is a 3D view that can be rotated, providing motion parallax, more effective than a static 3D view?

One of the primary objectives of the present study was to examine whether perceptual cues that differentiate 2D from 3D space help users organize information and remember where that information is located. Humans evolved in a 3D world. We place objects such as books, notes, and memos in various locations to be retrieved later. Ruddle, Payne, and Jones (1997) showed very similar pattems of learning between a virtual reality based environment and a real world environment. Thus, one could argue that a 3D interface for storing and 
retrieving information, although abstracted from the real world, should be more effective than a $2 \mathrm{D}$ interface.

The present study compared 2D and 3D representations of the same "deskscape", to determine if 3D cues benefit the user. Some past research (Mander et al., 1992; Robertson et al., 1998) seems to indicate that the piles we create on our desks provide information that helps us to remember the location of certain items. For example, we may remember that a certain report is in the back left comer of our desk toward the bottom of a pile. This type of structure is not possible with a $2 \mathrm{D}$ interface. Both the $2 \mathrm{D}$ and $3 \mathrm{D}$ displays in the present study were spatial in nature, yet they differed in the perceptual cues available to the user. Specifically, the 2D condition displayed documents and a desktop that lacked the illusion of depth. There were two different 3D conditions, both of which contained numerous perceptual cues that gave the illusion of depth. One of the 3D conditions, however, also included the cue of motion parallax, which allowed an assessment of performance when motion is added to a static 3D display. As discussed above, adding motion to a static 3D display can help to resolve certain ambiguities in the display and contribute to a more coherent mental image of the scene than a 3D display without motion.

Another objective of the present study was to examine the potential benefits of organizing and retrieving documents from a subjectively organized versus a preconstructed, or fixed, information space. The information spaces we create in everyday life (i.e., reports, books, and papers in our office) are highly personalized. An effective organization that we have created for our own use may be difficult for another person to use. Thus, it was expected that a subjective organization would yield better performance than one that was preconstructed and imposed on the user. 
An initial session, where half of the participants created their information space and half became familiar with a fixed one, was followed 24 hours later by a retrieval session, where participants were asked to find specific documents in the information space. In the retrieval session, participants interacted with the same information space as they did in the first session. The main dependent variables of response time and accuracy were measured in the retrieval phase of the study. During the retrieval phase, participants were shown specific documents and then asked to locate each one on the virtual desktop by clicking on the corresponding document. They were allowed to choose up to ten documents in their attempt to find the target document.

Participants were expected to exhibit better performance in the 3D conditions, with the best performance expected in the 3D condition with motion parallax. Thus, a main effect was predicted for display type.

It was also expected that a subjectively organized information space would produce better performance than a fixed space. Thus, a main effect was predicted in the organization condition.

In the fixed organization condition, increasing the number of perceptual cues was expected to show only marginal increases in performance. However, in the subjective organization condition, performance was expected to increase more dramatically as additional perceptual cues were introduced. 


\section{METHOD}

\section{Participants}

The participants for the present study were 60 undergraduate psychology students, consisting of 22 males and 38 females and ranging in age from 18-45 years. Everyone indicated that they had used the Internet. Everyone received partial course credit for his or her participation.

\section{Task}

The task for the present study was a computer software application designed specifically for the study. The software was written using the Borland Delphi 5 Enterprise Edition development environment, with a Virtual Reality Modeling Language (VRML) ActiveX

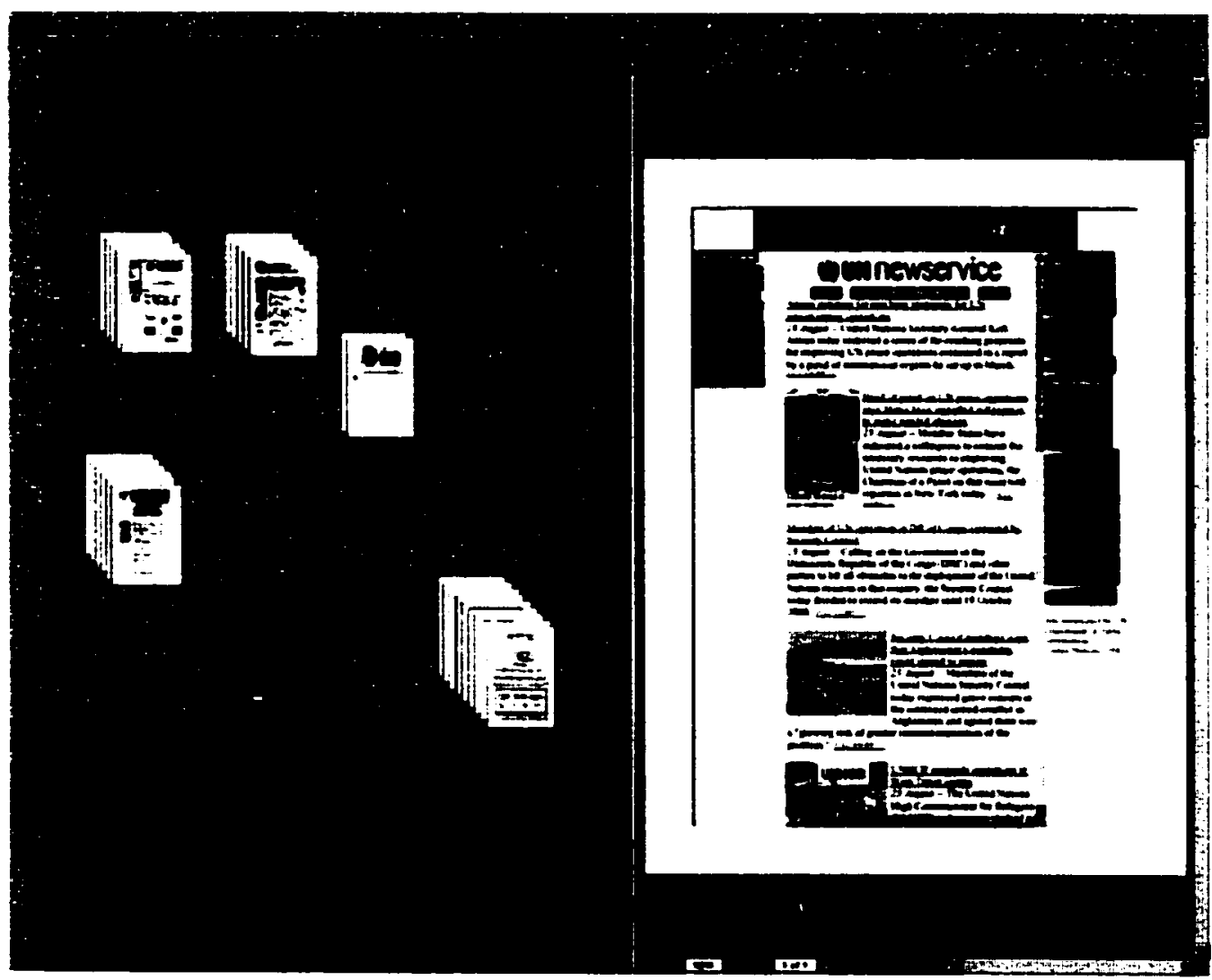

Figure 2. Two-dimensional desktop view. 
control from ParallelGraphics, Inc. (see http:/www.parallelgraphics.com/) to handle the rendering of the virtual desktop scene.

The scene displayed to the participant was a split screen view on one VDT display (see Figure 2). The right hand portion of the display contained a viewer for web documents. The dimensions for this part of the display were $42 \mathrm{~cm} \times 60 \mathrm{~cm}\left(23.6^{\circ} \times 33.6^{\circ}\right.$ of visual angle). A single page document was displayed in a manner similar to current web browsers. Although each document was a web page, all hyperlinks were disabled and participants could not navigate away from the current document. The left-hand portion of the display contained the virtual desktop scene in which the participant organized the documents into various piles. The dimensions for the virtual desktop portion of the display were $42 \mathrm{~cm} \times 60 \mathrm{~cm}\left(23.6^{\circ} \times 33.6^{\circ}\right.$ of visual angle). Each virtual document on the desktop had the same width to height ratio as an 8.5 "x11" $(21.6 \mathrm{~cm} \times 28 \mathrm{~cm})$ paper document. The stimuli that participants organized were 75 web documents taken from the Yahoo! Web site (see http://www.yahoo.com/) in July 2000. Figure 3 shows the proportions of documents sampled from each category. Appendix A lists the title of each of the 75 documents. All documents were reduced to a single page, with the criterion that the theme of each document was easily discemible from that one page.

\section{Desktops}

Three different versions of the desktop were used: a 2D desktop representation (2D), a 3D desktop representation with no motion (3D Static), and a 3D representation with motion parallax cues (3D Dynamic).

For the 2D condition, the interface was stripped of all but one depth cue and resembled a bird's eye view of a desktop. Thus, documents only appeared as $2 \mathrm{D}$ rectangular objects with no volume (see Figure 4). Documents within a pile were arranged and offset from the top and 


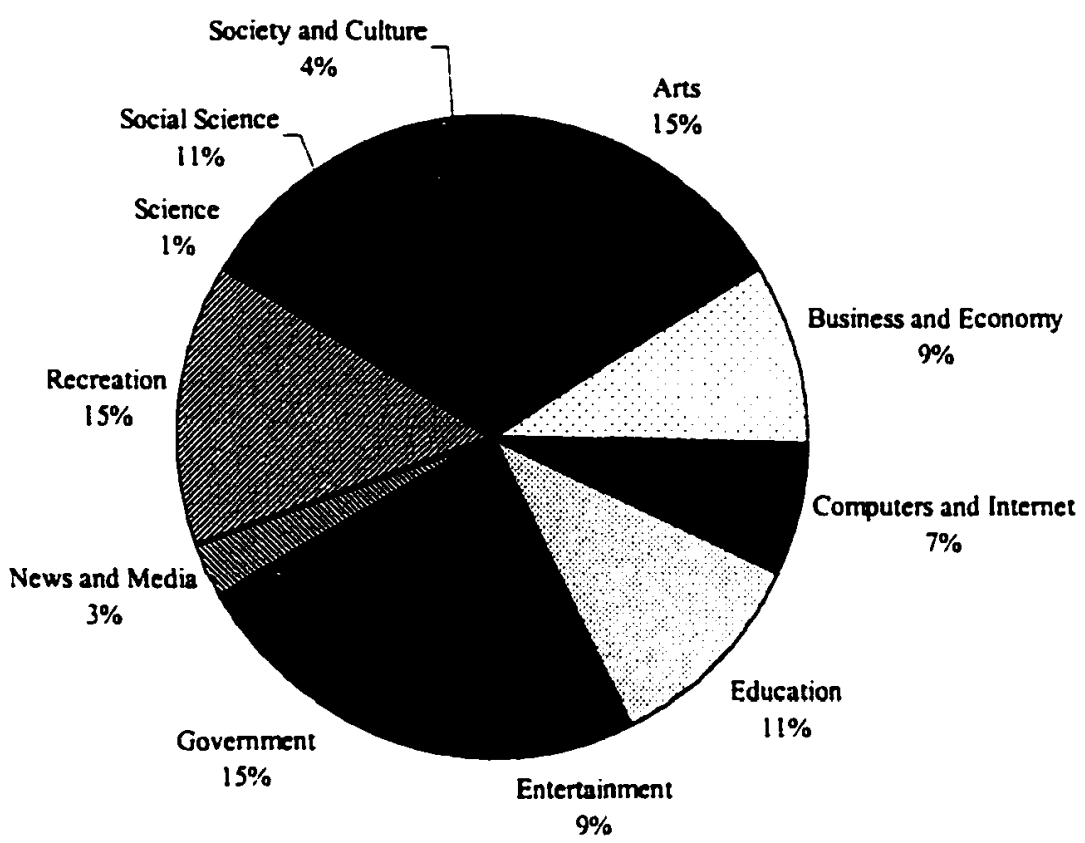

Figure 3. Categories sampled from Yahoo! web site.

side, consistently as each new document was placed on the pile (see Figure 2). Thus, the only cue to depth provided was occlusion and was included because that cue is available on all standard 2D desktop interfaces and it also allowed consistency of response across desktop conditions in the retrieval session.

In both 3D conditions, each document possessed volume (see Figure 5) in order to facilitate the perception of height in each pile so that participants could easily determine the approximate number of documents in a pile based on the 3D cue of height. For the 3D static condition, the desktop and documents appeared as static objects in 3D space (see Figure 6). Specifically, the perceptual cues of height in plane, linear perspective, relative size, and textual gradients differentiated the 2D and 3D conditions. The 3D dynamic condition possessed all of the cues of the 3D static condition, with the additional cue of motion parallax obtained through simple predefined and automatic rotations of the desktop. As discussed above, a 3D 


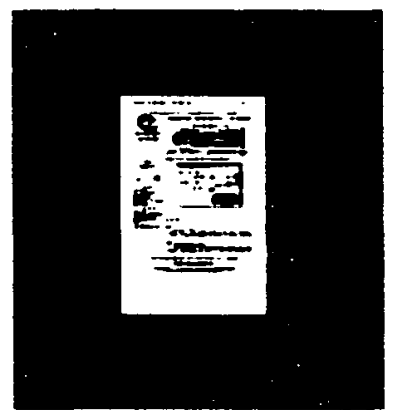

Figure 4. Single document in 2D condition.

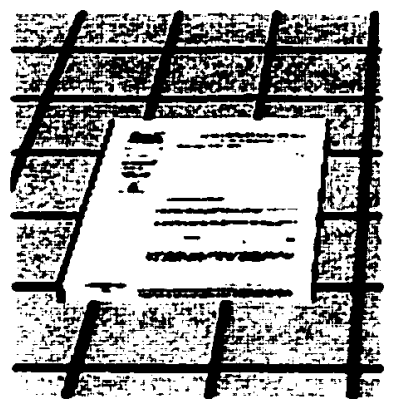

Figure 5. Single document in 3D condition.

display can offer a richer environment than a 2D without increasing cognitive demands on the user. Also, adding motion to a static 3D display can resolve perceptual ambiguities and help to create a more coherent mental picture of the scene. Upon moving to another document, the scene for the $3 \mathrm{D}$ dynamic condition was automatically rotated to one side or the other approximately 45 degrees and then back to center. This rotation process took $3.6 \mathrm{~s}$. The direction of rotation altemated for each successive document. The participant's view was still somewhat restricted, only differing from the 3D static condition in the changing viewpoint and the motion parallax that occurred while the scene was rotating. To equalize exposure time to the stimuli across conditions, there was also a $3.6 \mathrm{~s}$ delay between documents in the 2D and 3D static conditions.

\section{Organization}

Organization was manipulated in two ways: subjective organization, in which the participant had control over how documents were organized in the information space, and fixed organization, in which the participant was required to interact with a preconstructed information space. For the subjective organization condition, as each new document was displayed on the right side of the screen during the organization phase, the participant studied its content and 
placed it on the virtual desktop at a location of their choice. Clicking the mouse on the desktop itself generated a virtual document on the desktop at the point of the mouse click, thus creating a new pile. Clicking on an existing pile caused a virtual document to be generated as the topmost document on that pile. Documents being placed on an existing pile could only be placed as the topmost document. The software handled the task of aligning documents in a given pile so that each pile was constructed as a neat stack of documents during the task. For the fixed organization condition, participants studied a preconstructed information space and could not change either the organization or locations of piles of documents on the desktop.

For all conditions during the first session, participants could view a thumbnail image of a

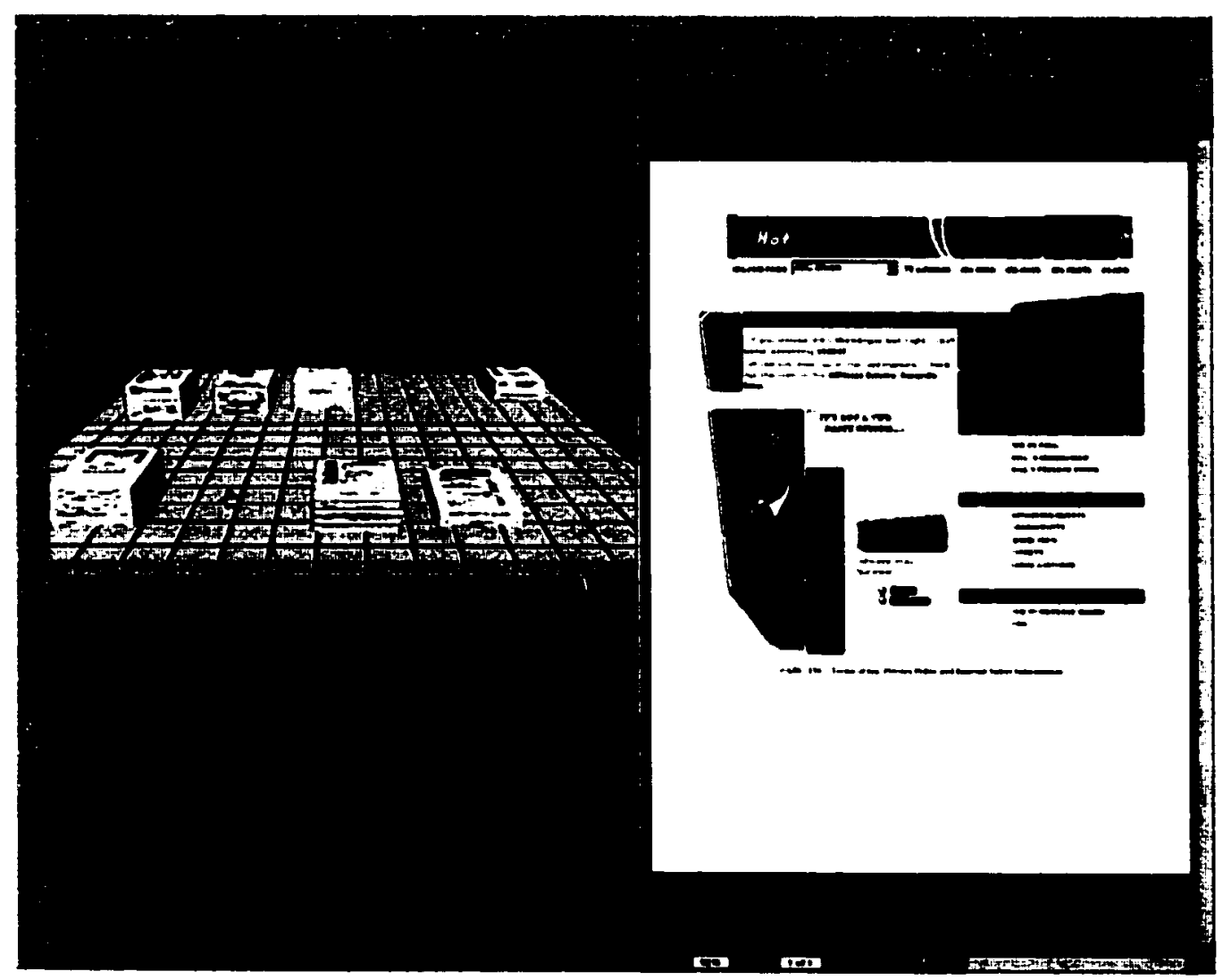

Figure 6. Desktop appearance in 3D conditions. 
document that was already in a pile on the desktop. This allowed participants to reacquaint themselves with the contents of a pile when deciding where to place a new document. By depressing the 'Ctrl' key on the keyboard and placing the mouse cursor over a document on the desktop, a thumbnail image of the document appeared in a small viewer on the right half of the screen (see Figure 7). No mouse buttons needed to be pressed; the mouse cursor just hovered over the desired document. This method worked for any document at any location within a pile. However, in the fixed organization condition, participants could not view thumbnails of all documents. They could only view documents that had already been shown in the larger main viewing window. In Figure 7, for example, the user has depressed the 'Ctrl' key, and is holding the mouse cursor (circled) over a document. The contents of that document are shown in the small viewer on the right of the screen. In this example, the topmost document of the pile is shown, but as stated above, other documents in a pile can be viewed in this way. Note that the circle and lines are used for illustration and did not appear in the computer task.

\section{Procedure}

The test setting was an anechoic room containing only the computer for the task, a desk and a chair. Each participant was seated $40 \mathrm{~cm}$ from the computer display.

There were two separate sessions. In session one, participants were presented with the 75 web documents described above. Each document was presented in succession on the right half of the screen. The presentation of a given document and the participant's response to the document (described below) was considered a single trial. Instructions to participants are shown in Appendices B-E.

Each participant was randomly assigned to one of the desktop cue conditions, (2D, 3D 
Static, 3D Dynamic). Half of those in each desktop condition were assigned at random to either the subjective or fixed organization condition. Prior to the first session, a document preview was shown to each participant on the computer screen, consisting of a $6 \mathrm{~s}$ presentation of 30 of the 75 documents. This preview was shown in an entirely different window than the task, and no desktop information was visible. Each participant was told that the preview documents were representative of the overall set, and instructed simply to glance over each document and become familiar with the types of documents displayed. They were not told what they would be doing with the documents later. Session one was started following the preview. During the first session participants in the subjective organization condition studied each document presented on the right hand side of the display and placed it

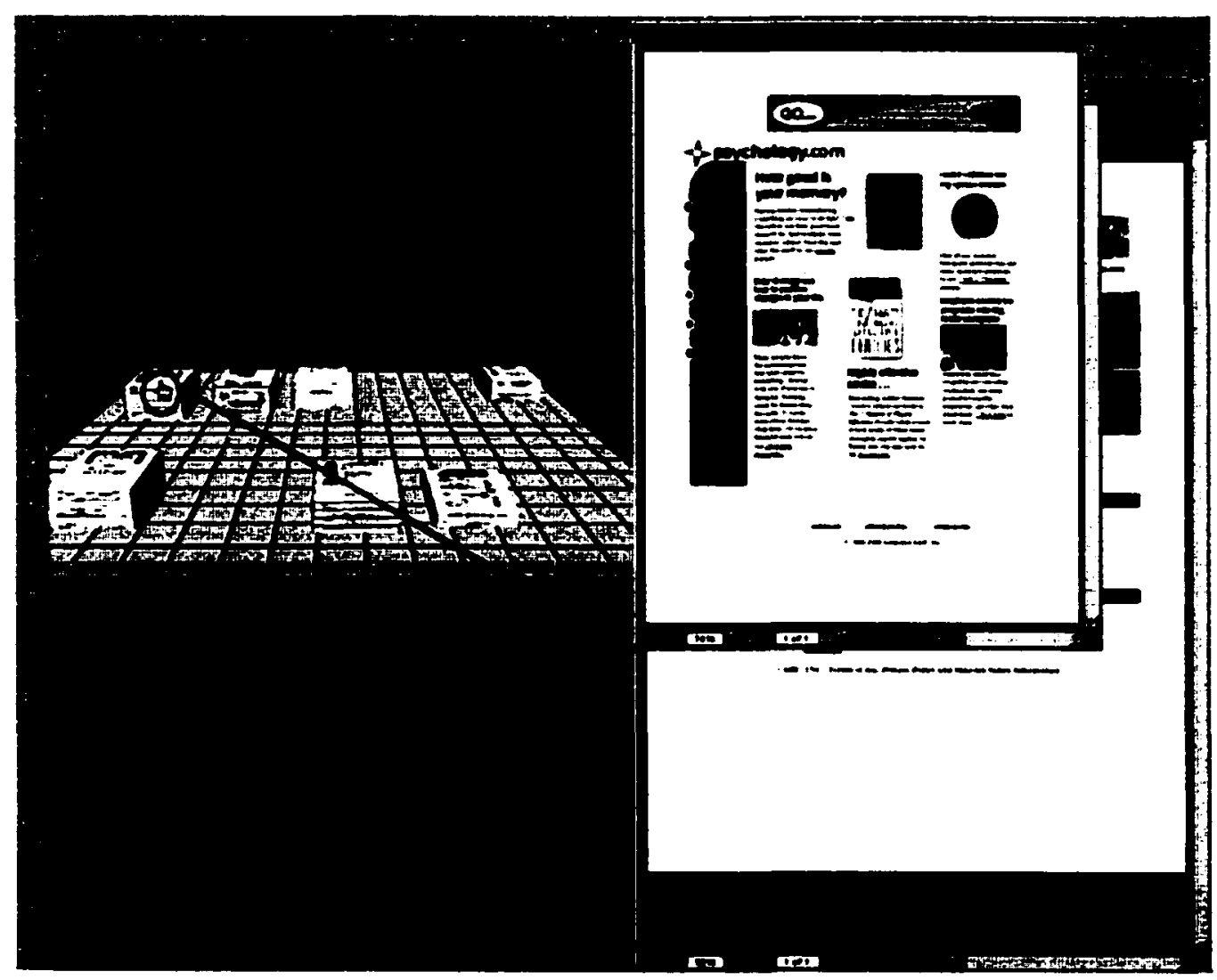

Figure 7. Viewing a document on the desktop. 
on the desktop on the left half of the screen. After each document was placed on the desktop, the next document was automatically shown in the right-hand viewing pane. Once a document was placed on the desktop, its location could not be changed. Participants were instructed to use any organization scheme they wished, as long as they adhered to the requirement of creating piles based upon the content of the documents. They could create as many piles as they desired, put as many documents into each pile as they desired, and place each pile anywhere on the desktop they desired.

The participants in the fixed organization condition did not have control over organizing the piles of documents on the virtual desktop; all documents were already organized into piles when the session began. The pile configuration was taken from one of two participants run during a pilot session. Two different pile configurations were used. As each document was presented, one-by-one, on the right half of the display, the existing location of the virtual document on the desktop was highlighted in red so the participant could become familiar with the location of the document on the desktop. The participant was not able to aiter the location of any of the documents or piles. Participants clicked a button on the display to navigate to successive documents.

Session two was the retrieval phase of the experiment and occurred 24 hours after the first session. In this session, all participants were asked to locate 26 of the 75 documents in the pile structure on the desktop. Each document they were asked to locate (the target document) was presented in the right half of the screen, similar to the first session. As each document was presented, the participant clicked the mouse on the virtual document on the desktop that they thought represented the target document. The pile structure on the desktop was the same one the participant created or interacted with in session one. Participants were 
encouraged to find the document in the fewest number of attempts possible and could make up to a maximum of ten attempts. After each attempt, feedback was displayed on the screen. If the participant clicked on an incorrect pile, the feedback stated, "Incorrect Pile," followed by the phrase "and closer" or "and farther away"; meaning closer to or farther away from the correct document since the last attempt. If the participant clicked on the correct pile, the feedback stated, "Correct Pile". Also, after each attempt the attempt number was displayed along with the other feedback. When the participant located the correct pile, they were presented with the feedback, "CORRECT DOCUMENT!", and a sound was played through the computer speakers. The sound file was titled "tada.wav", and is included on the Microsoft Windows NT Workstation 4 installation CD-ROM. Response times were measured beginning with the initial appearance of the document on the right-hand side of the display. A response time was recorded for the first document selected and also for the correct document selected in the information space on the left. If a participant did not find the correct document within a maximum of ten attempts, the response time for the tenth attempt was used for that trial. An accuracy measure, described below, was also recorded for each document the participant was asked to locate.

\section{Criteria for Choosing Retrieval Documents}

As stated above, during the retrieval session, participants were asked to retrieve 26 of the 75 documents. This was judged to be a sufficient number of documents to adequately test participant's memory. Ideally, documents in this subset would be representative of the entire set in terms of their "categorizability". For example, the theme or category of some documents may be quite obvious, while the theme of other documents may be more ambiguous. Memory for the location of a well delineated document, such as a travel web site, 
in a pile of other well delineated documents may be better than memory for more "fuzzy" documents, such as music education sites that could be put into multiple categories (i.e., music and/or education). Thus, a sample of documents containing approximately equal numbers of documents that were easy or difficult to categorize were obtained.

A statistical procedure was used to aid in the document selection. In this procedure, a scalar standardized index was assigned to each document in the set indicating the relative strength of categorization for that particular document. The statistic, termed the strength of categorization index or $\mathrm{SOCl}$, ranged from 0.00 to 1.00 , with higher values assigned to documents that were relatively easy to categorize, and low values assigned to documents that were relatively difficult to categorize. As a general note, the index values generated were specific to the set of documents being examined, and were not generalizable beyond that set. The calculation of this statistic is explained below.

In a pilot test, participants placed single-page paper printouts of the documents into piles on a desktop. They were instructed to simply create piles of documents based on the content of the documents. Themes of the piles, number of piles, and number of documents in each pile were left to their discretion. The document groupings were recorded for each participant.

A $75 \times 75$ document-by-document proximity matrix of the categorization of document sets across participants was created. Each cell in the matrix represented a document-todocument pairing and the value of a given cell indicated the number of times those two documents were placed in the same pile together. This matrix was the starting point for calculating the strength of categorization index. First, a cutoff value was specified, below which the values in a particular cell would be excluded from analyses. This allowed a cleaner statistic by discounting possibly spurious document pairings. For the present study, cell values 
of 1 , which indicated that a document was paired with another only once, were excluded from analyses. Cell values of zero were automatically excluded from analyses.

Next, a mean was calculated for each document to represent the typical number of times the document was paired with any other document. To obtain this mean, one row (or column) of the proximity matrix (representing a specific document) was summed, excluding from the average any cell values at or below the cutoff of $l$. This sum was then divided by the number of cells comprising the sum.

Higher values indicated that people paired a given document with only a few different documents. Thus, a higher value indicates higher agreement and consistency across people. A lower value indicated that people grouped the document with relatively higher numbers of different documents and that the category/theme of the document was interpreted more ambiguously.

The theoretical maximum value of this average is equal to the number of participants $(N)$ in the study. Thus, the average was standardized by dividing by $\mathrm{N}$, creating the final scalar index of categorization for each document. This statistical procedure closely matches the method by which a cluster analysis groups documents together based on distance values. A cluster analysis was performed on the pilot test data, the results of which are shown in Appendix F. Indeed, the groupings that showed small distances between the documents (strong grouping) contained documents with a relatively high SOCI. Groups that the cluster analysis showed to be more questionable and ambiguous generally contained documents with a low SOCI.

For the present study, the documents were rank ordered based on their categorization indexes, and then every third document was chosen to be included in the retrieval set. 


\section{Equipment and Apparatus}

The experimental task was run on a custom built dual processor Pentium III computer with a SuperMicro P6DBU motherboard, 2 Pentium III $550 \mathrm{MHz}$ processors, and $512 \mathrm{MB}$ of SDRAM. The operating system on the computer was Microsoft Windows NT 4.0 (Service Pack 6). The display was a Hitachi SuperScan Elite 19-inch monitor, driven by a Creative Labs 3D Blaster Banshee $16 \mathrm{MB}$ AGP video card and an 85 Hertz monitor refresh rate. The screen resolution was $1280 \times 1024$ pixels. Mouse sensitivity was set at approximately 460 pixels of mouse cursor movement per inch of physical movement of the mouse.

\section{Experimental Design}

The present study used a 2 organization (subjective, fixed) $x 3$ cues (2D, 3D Static, 3D Dynamic) between-subjects factorial design. The main dependent variables were measured in session two (retrieval phase). Accuracy was measured as well as response time to the nearest tenth of a second.

The accuracy measure was the length of the vector that connects the target and selected documents. The centerpoints of the target and selected documents were specified as points in either 3D or 2D space and the length of the vector connecting those points defined accuracy. The location on the document at which the participant clicked the mouse was not important; thus, a consistent point on each document was always used to form the vector. This definition of accuracy allowed a finer grained analysis of responses than if a dichotomous "correctincorrect" accuracy measure had been used. For example, if a participant in the 3D condition did not remember where a document was on their desktop, he or she might know that it is somewhere toward the back right comer. A simple measure of correct or incorrect responses would not reveal the spatial proximity of their choices. A vector measurement, however, 
provides a more precise measure of how close in 2D or 3D space the participant was to the correct response. Shorter vector lengths indicated more accurate memory of document location.

Since each participant was allowed up to ten attempts on each trial to find the correct document, there are a number of methods by which one could calculate vector length and response time for each trial. One such method is to average the vector lengths of all attempts in a trial and use that value as the accuracy measure for the trial. However, this method may have been tainted in the present study due to limitations of the computer interface. For example, in the 3D-subjective conditions it was possible to arrange one's desktop during the organization session such that some documents (i.e., those at the back of the desktop) were completely obscured. Thus, it would not be possible during retrieval to successfully select such a document. This limitation could artificially inflate the length of the vector lengths observed.

Another method of calculating the vector lengths for each trial is to simply include only the first attempt of each trial. The instructions to each participant emphasized locating the target document in as few attempts as possible, so presumably the first attempt of each trial was a best guess for all participants and would be representative of memory for document locations. 


\section{RESULTS}

\section{Preliminary Analyses}

As previously stated, two different pile arrangements taken from pilot data were used in the fixed condition. This was done to ensure that pile arrangement itself did not contribute to performance. Initial analyses revealed no significant effect of pile arrangement, $t(28)=1.016$, $p>.05$, thus all analyses were collapsed across the two pile arrangements in the fixed condition. There were no significant differences between the conditions for time spent on the task in session one or for the mean number of times that documents were previewed using the thumbnail viewer. For all of the analyses reported below, a significance level of $\alpha=.05$ was adopted and significant main effects were analyzed further with Tukey Type A post hoc tests.

\section{Accuracy}

A 2 organization (subjective, fixed) $x 3$ cues (2D, 3D Static, 3D Dynamic) between subjects ANOVA was performed on the mean accuracy of each participant's first attempt on each trial. These results are summarized in Table 1. A significant main effect was observed for organization, $F(1,54)=35.491$. Accuracy was significantly greater for subjective organization $(M=0.892)$ than for fixed organization $(M=1.839)$. The ANOVA also revealed a

Table 1: Source of Variance for Vector Length of First Attempt

\begin{tabular}{lllllll}
\hline Source & Type III SS & df & MS & F & $\omega^{2}$ & $1-\beta$ \\
\hline Cues & 4.356 & 2 & 2.178 & $5.743^{*}$ & 0.087 & 0.848 \\
Organization & 13.460 & 1 & 13.460 & $35.491^{*}$ & 0.317 & 1.000 \\
Cues x Organimation & 2.542 & 2 & 1.271 & $3.351^{*}$ & 0.043 & 0.609 \\
S(Cues x Organization) & 20.479 & 54 & 0.379 & & & \\
\hline
\end{tabular}

$* p<0.05$ 
significant main effect for cues, $F(2,54)=5.743$. Post hoc tests showed no difference between the 3D static $(M=1.619)$ and 3D dynamic $(M=1.484)$ conditions. There was, however, a significant difference between each of the 3D conditions and the 2D condition $(M=0.992)$.

The interaction between organization and cues was also significant, $F(2,54)=3.351$. This is illustrated in Figure 8. An analysis of simple effects revealed no difference among cues for subjective organization, $F(2,27)=0.348, p>.05$. There were however, significant differences among cues for fixed organization, $F(2,27)=8.752, p<.05$. Post hoc tests on this simple effects analysis showed that in fixed organization, participants in the 2D condition were significantly more accurate than those in the 3D static and 3D Dynamic conditions. There were no differences between the 3D static and 3D dynamic conditions.

\section{Response Time}

The response time measure was the number of seconds elapsed from the document appearance on the screen until the participant found the correct document. A 2 organization (subjective, fixed) $x 3$ cues (2D, 3D Static, 3D Dynamic) between subjects ANOVA revealed no significant differences for any of the effects. These results are summarized in Table 2.

Table 2: Source of Variance for Response Time for Correct Responses

\begin{tabular}{lllllll}
\hline Source & Type III SS & df & MS & F & $\omega^{2}$ & $1-\beta$ \\
\hline Cues & 9.116 & 2 & 4.558 & 0.078 & 0.061 \\
Organization & 92.294 & 1 & 92.294 & 1.579 & 0.235 \\
Cues x Organization & 69.045 & 2 & 34.523 & 0.590 & 0.143 \\
S(Cues x Organization) & 3157.315 & 54 & 58.469 & & & \\
\hline
\end{tabular}

$* \mathrm{p}<0.05$ 


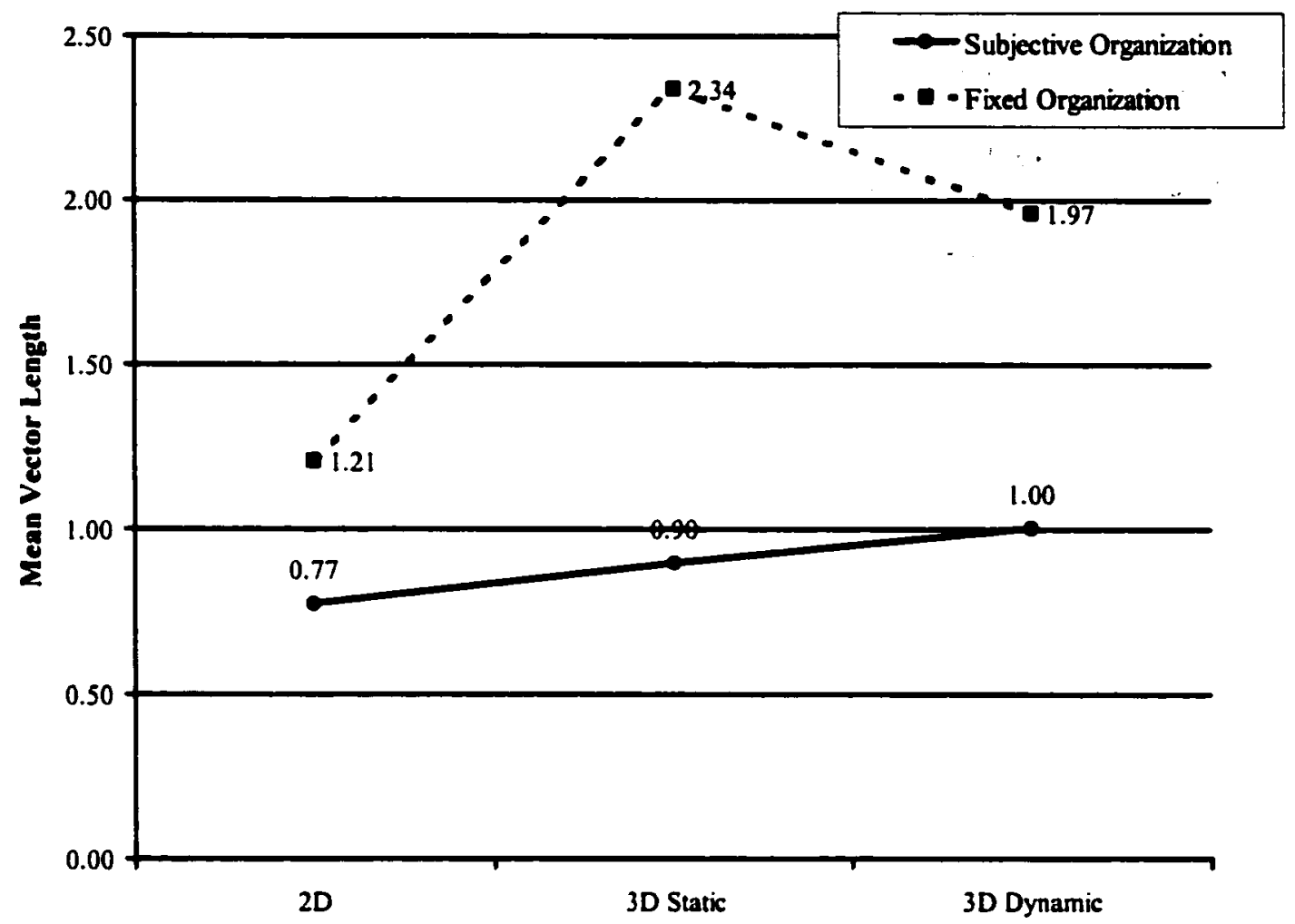

Figure 8. Mean vector length for cues as a function of organization.

\section{Number of Attempts}

A 2 organization (subjective, fixed) x 3 cues (2D, 3D Static, 3D Dynamic) between subjects ANOVA was performed on the mean number of attempts of each participant. The results are shown in Table 3. This analysis revealed a significant main effect for cues, $F(2,54)=$ 11.404. Post hoc tests showed no difference between the 3D Static $(M=5.329)$ and 3D Dynamic $(M=5.425)$ conditions. The 2D condition $(M=3.981)$ showed significantly fewer attempts than both 3D conditions. The ANOVA also showed a significant main effect for Organization, $F(1$, $54)=11.656$. Subjective organization $(M=4.530)$ showed significantly fewer attempts than fixed organization $(M=5.293)$. 
Table 3: Source of Variance for Number of Attempts

\begin{tabular}{lllllll}
\hline Source & Type III SS & df & MS & F & $\boldsymbol{\omega}^{2}$ & I $\boldsymbol{\beta}$ \\
\hline Cues & 26.079 & 2 & 13.039 & $11.404^{*}$ & 0.232 & 0.990 \\
Organization & 8.754 & 1 & 8.754 & $7.656^{*}$ & 0.074 & 0.776 \\
Cues x Organization & 5.033 & 2 & 2.517 & 2.201 & & 0.430 \\
S(Cues x Organization) & 61.744 & 54 & 1.143 & & & \\
\hline
\end{tabular}

$* p<0.05$

\section{Cluster Analysis and Strength of Categorization Index (SOCI)}

The document strength of categorization indexes (SOCI) for the pilot data were significantly correlated with the strength of categorization indexes of the subjective condition of the present study, $r(74)=.878, p<.05$. This indicates that participants in the pilot study and the present study were consistent in how they categorized the documents. The cluster analysis of the pilot study and present study also revealed similar groupings of the documents (see Appendix F and Appendix G).

To further compare how the documents were categorized in the pilot and actual studies, a finer-grained, document-by-document analysis was performed. A difference matrix was computed from the $75 \times 75$ pilot study proximity matrix and the $75 \times 75$ present study proximity matrix. Each of the two proximity matrices used was comprised of proportions as opposed to absolute frequencies in order to obtain a more standardized difference value that could be compared across populations. This difference matrix allows a document-by-document analysis of the grouping patterns between the pilot and current study, whereas the SOCI only provides an overall statistic for each document. For example, if a given document is grouped with each other document with relatively similar frequency in both pilot testing and the 
present study, then the mean difference for that document will be low. If a given document is grouped with other documents in a different manner from pilot testing to the present study, then the mean difference will be high. A given document could possess the same SOCI value for pilot testing and the present study, leading us to believe there were no differences between pilot testing and the present study in how consistently participants categorized that document. However, the mean difference (taken from the difference matrix) for that document's grouping could be high, indicating that participants grouped the document in a different manner from pilot testing to the present study. A high negative correlation between the mean grouping difference and the SOCI of each document (i.e., low mean differences for highly categorizable documents, and higher mean differences for less categorizable documents) would indicate that the SOCI agreed with the finer-grained, document-by-document pattem of grouping. This would also show that the SOCI was representative of the categorizability pattern of documents. Indeed, there was a significant negative correlation, $r(74)=-.71, p<.05$. 


\section{DISCUSSION}

The present study had two main objectives: (a) to examine the potential benefits of organizing and retrieving documents from a subjectively organized versus a fixed information space, and (b) to examine whether the presence of perceptual cues that differentiate 2D from 3D space help users organize and later retrieve information.

\section{Organization}

The information spaces that we create for ourselves in everyday life (i.e., the arrangement on our desks, icons on our computer desktops) are highly personalized. Although this subjective arrangement may be quite efficient for our own use, others would most likely find our organization structure quite difficult to use (Mander et al., 1992). In the present study, it was expected that retrieval performance for subjectively organized information spaces would be better than for preconstructed spaces, which is exactly what the results showed. So in certain types of tasks, including the present task, forcing users to interact with a preconstructed information space is less effective than presenting the same information to the user in a less defined manner and allowing them to organize it themselves.

There are numerous strategies for information gathering/storage/retrieval tasks. However, the present study only deals with information that the user finds, uses, and stores for later retrieval. Examples are phone/e-mail lists, reference web sites, and sports, weather, or stock quote web sites. The user may retrieve this information many times and never truly dispose of it. With this type of task, retrieval of information would benefit from providing users with a method for building their own personal structure of information on the site. For example, a web site containing research materials that a user visits often would benefit users by allowing them to build their own personal information space of the references that they 
find. Each time a given user visits the site, they would be able to efficiently retrieve the information from their own meaningful, personalized structure.

\section{Perceptual Cues}

Capitalizing on our lifelong experience with 3D environments and objects seems like a natural approach to interface design. As mentioned previously, many designers have accepted and used this approach without much question. The present study empirically tested this assumption and found that overall, 2D arrangements were superior to both 3D Static and 3D Dynamic ones. More important though, perceptual cues interacted with organization. For subjectively organized spaces, the presence or absence of perceptual cues did not affect memory of document locations. For fixed information spaces, a 2D spatial arrangement was superior to both 3D static and 3D Dynamic arrangements. The 3D arrangements were shown to be statistically equal to one another. Thus, the addition of perceptual cues for fixed displays hindered memory of the locations of documents on the desktop. These pattems of performance were contrary to the hypotheses. It was expected that more perceptual cues would help all participants, but especially those in the subjective organization condition.

Instead of a strategy of attempting to remember the location of each document, it is possible that participants adopted a more gross strategy of remembering document locations. Specifically, participants may have attempted to remember only the location of each pile on the desktop and not the contents of each pile. Knowledge of pile themes and pile locations could be a natural by product of attempting to remember individual document locations. For example, during the debriefing session, many participants seemed quite able to point to a given pile and state its theme (i.e., "education" pile and "travel" pile were commonly stated themes), although they were not explicitly instructed to attend to the pile itself. This pile-level 
strategy would be a less demanding task than trying to remember the locations of all of the documents.

To verify this possibility, the data were examined for evidence of a pile-level strategy. The number of times participants selected the correct or incorrect pile on their first attempt was determined for each cue condition. The results are shown in Figure 9. The frequency reflects the number of trials summed across all participants for a given condition. In the $2 \mathrm{D}$ condition, the correct pile was selected more often than in the 3D Static condition, $\chi^{2}(1,749)$ $=8.760, p<.01$. However the 2D and 3D Dynamic conditions were statistically equivalent, $\chi^{2}(1,783)=2.821, p>.01$. A significance value of $\alpha=.01$ was used here due to the multiple tests performed and the increased probability of Type I error. These results are generally consistent with the finer grained vector length analysis. Given that the $2 \mathrm{D}$ desktops generally resulted in better performance, one can call into question the face validity and simplistic approach of attempting to create computer interfaces that mimic the real world.

\section{Ways in Which People Do Work}

One explanation for the superiority of the $2 \mathrm{D}$ desktop may lie with the way people do their work in the real world. Even though people live and work in a 3D world, they generally tend to navigate the environment on 2D planes parallel to the surface of the earth (Waterworth \& Chignell, 1997). Thus, although our natural world is 3D, people may need training to effectively conceptualize their work in three dimensions, especially within 3D flat panel displays. Some research supports this suggestion. For example, Poblete (1995) tested the amount of incidental learning that took place with a physical 3D Drum-shaped hierarchy and a 2D menuing style hierarchy. With the 2D hierarchy, participants could traverse the hierarchy but only a single branch was visible at any moment. The 3D hierarchy showed all branches of 


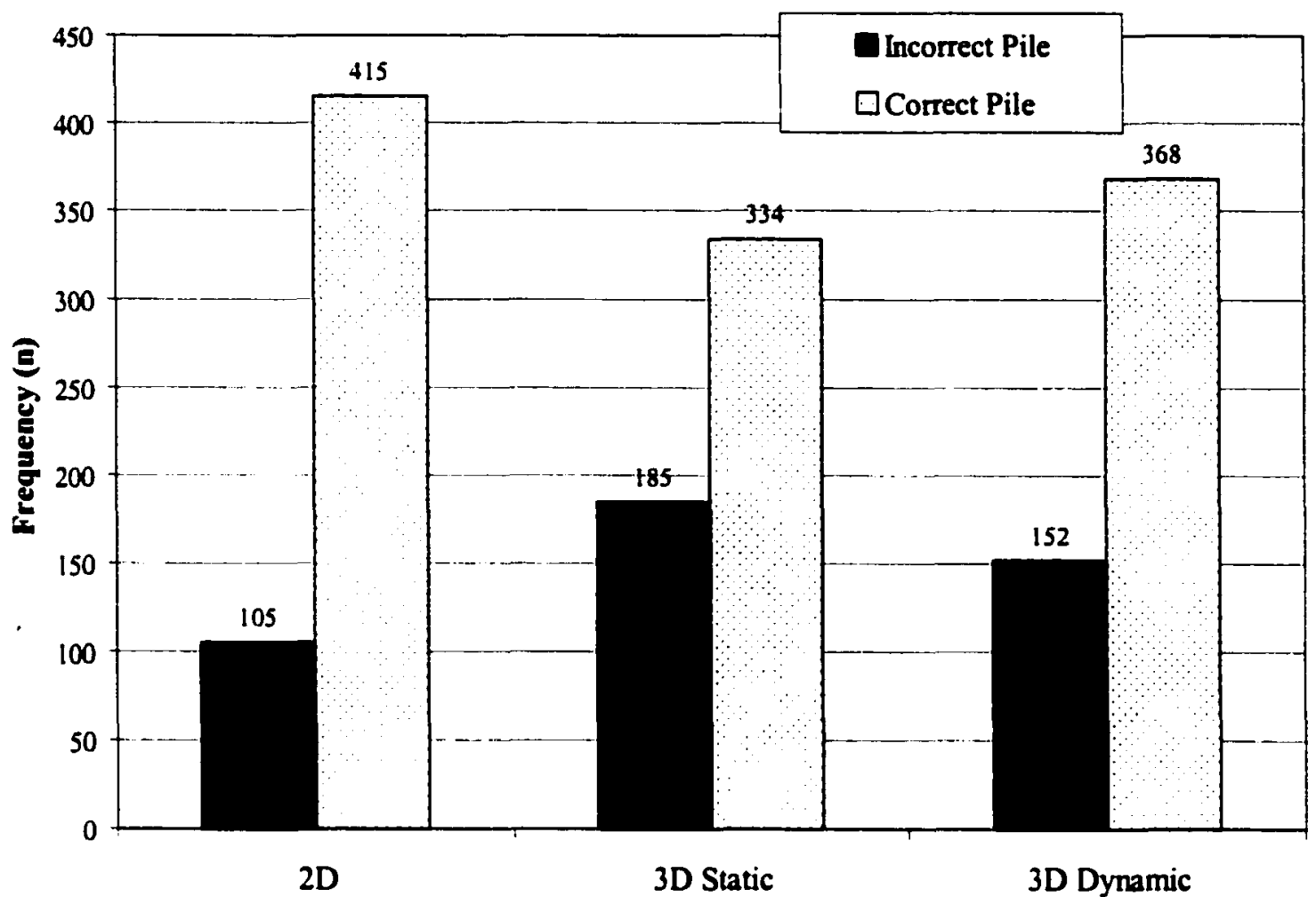

Figure 9. First attempt pile selection as a function of cues.

the hierarchy. Participants first interacted with information in one of the hierarchies and were then asked to sort the same unstructured information into a hierarchical arrangement. The degree to which a participant could reproduce the hierarchy was the indicator of learning. No learning was found in the $3 \mathrm{D}$ condition, but the $2 \mathrm{D}$ condition did produce significant leaming.

Research on mental imagery and mental maps may also provide insight to the present results. The current hypotheses were based on the tenet that 3D documents on a desktop closely matched the mental model of users and that displays more like our 3D world would promote better performance. However, this assumes that individuals' mental representations of the task is an analog, or true-to-space representation of the real world. This is currently a controversial point in the literature (see Kosslyn, 1980), and much research shows this assumption may be flawed. There is evidence that peoples' mental representations of large 
scale environments (i.e., urban city layouts) are distorted, abstract, and hierarchical (Chase, 1986). Lynch (1960), for example, showed that people in urban cities tend to conceptualize their surroundings in terms of abstract elements which he categorized as paths, edges, districts, nodes, and landmarks. The distortions people made in recalling relative spatial layouts of areas of their city provided evidence that spatial information was represented more abstractly or symbolically rather than pictorially or spatially. Other studies have shown systematic distortions in mental maps and also suggest that an object's location may be remembered descriptively or symbolically (Baird, Wagner, \& Noma, 1982; Howard \& Kerst, 1981; Kosslyn, Pick, \& Fariello, 1974; Moar \& Bower, 1983; Newcombe \& Liben, 1982; Tversky, 1981).

In an example of hierarchical representation of spatial knowledge, Stevens and Coupe (1978) showed that residents of San Diego, Califomia believed the compass direction of Reno Nevada to be north-northeast, when in fact Reno is north-northwest of San Diego. Individuals' judgements were affected by the larger surrounding geographic region and they also inferred the location from nonspatial facts, namely the relative locations of Califomia and Nevada to one another. Even if people utilize a mental analog image, these types of errors show they most likely derive the image from more abstract knowledge.

Spatial information, at least of real, large scale environments, may be encoded abstractly and hierarchically simply to make the spatial representation more mentally efficient for recall and making inferences (Chase, 1978). Storing an analog of a spatial layout or an abstract representation of all possible spatial relationships within a layout, would be quite mentally taxing if not impossible. Short term memory capacity may severely limit our ability to maintain spatial relationships and people most likely maintain only a few spatial relationships 
for a given spatial image. Thus, from this capacity limitation we may assume that storage and retrieval from long term memory would also be degraded (Chase \& Ericsson, 1981). This leads to the implication that mental representations of spatial relationships are necessarily impoverished and schematic (Chase, 1986). When discussing retrieval of spatial information in this way it is important not to confuse a distorted encoding of the information with a general failure of memory (Tversky, 1981).

Unless explicitly instructed otherwise, people may naturally gravitate toward less spatial methods, such as a list learning strategy or mnemonics, for remembering the relative positions of objects. Peterson (1975) instructed participants to either imagine particular letters in cells of a $4 \times 4$ matrix or they were shown an actual matrix. In both conditions, the highest recall accuracy occurred for letters in the comers of the matrix: the most spatially salient locations. No serial position effects for the letters were found; thus, researchers concluded that participants were using mental imagery to remember locations of letters. In a separate but similar control experiment, participants were told where the letters were located on the imaginary matrix but were not instructed to use mental imagery as a strategy for remembering. Those results did show a serial position effect, and did not show greater accuracy for the comers of the matrix, indicating that participants may have used a list leaming type of strategy. Pinker and Kosslyn (1978) showed that people can learn the locations of objects suspended in a 3D box and then recall those objects by mentally scanning the scene with similar response times to how they would scan and recall objects from the actual scene. This again shows that people can use mental imagery or a mental map strategy to leam and store spatial information. However, if people are left to their own devices most may resort to something other than spatial methods. 
Assuming the above results hold true for smaller, but still somewhat complex environments such as the desktop used in the present study, realistic 3D scenes may be incompatible with how users are storing the spatial information in the scene, especially since there is a fairly large set of documents to remember. Perhaps the more simplistic 2D representation, even though still spatial, is better suited for retrieval of information. Even though the web document metaphor implies real world paper documents, and one might assume that realistic 3D interfaces would aid users, this was not true in the present study. People obviously are naturally immersed in a 3D environment and have much experience manipulating objects in this real world environment. However, we cannot make the assumption that people conceptualize objects and processes in their world using a threedimensional scheme. The current study supports this point.

Post experiment discussions with participants of the present study also suggest an advantage for $2 \mathrm{D}$, or perhaps a disadvantage for 3D. Upon debriefing and illustrating the different experimental desktops to participants, a number of people stated that the 3D desktops looked more difficult than the 2D desktop. One person stated that the 2D desktop looked "more like I do things", meaning more like she conceptualizes and does work. Another participant said that she organizes her real world information space on a corkboard attached to a wall rather than a desktop, because a desktop she said would "get too messy". The 2D desktop indeed could resemble the layout of information on a corkboard. A third participant stated that in the 2D desktop, all of the information was "right there", meaning each document was the same size and each pile was equally accessible, as opposed to either of the 3D desktops in which documents receded into the distance. Numerous other participants in the $2 \mathrm{D}$ desktop condition stated during debriefing that they thought the $3 \mathrm{D}$ desktop 
appeared to be more complex and difficult to work with, but none could specify the exact reason.

In the present study, perceptual cues did not affect those participants who constructed their own document piles; hence, 2D was superior only within a fixed organization scheme. Perhaps the active nature of subjective organization facilitated such a strong memory of document location that variations in perceptual cues would neither hinder nor aid performance.

\section{Benefits of Motion Parallax}

It was hypothesized that adding motion to a static 3D display would improve the overall cognitive map of the space and presumably aid performance. This was not shown to be true in the present study as there was no significant difference between the 3D static and 3D dynamic conditions. Thus, adding motion to a static 3D display did not benefit users. The general trend seems to suggest that adding motion could offer a very slight benefit to users (see Figure 8), but future research would need to explore this.

Two important possibilities discussed above were (a) that a 3D arrangement may not coincide with most users' mental models of information workspaces, or (b) that people may be encoding spatial information in a nonspatial manner. Given either of these possibilities, one would not expect that adding yet another type of perceptual cue (i.e., motion) would be beneficial.

\section{Computer Interface Limitations}

Ideally, differences in perceptual cues should have been the sole source of distinction among the desktops used in the present study. However, due to the constraints of the current methodology and the computer task itself, a number of factors besides the perceptual cues 
differentiated the 2D and 3D desktops. These factors will be discussed below.

\section{Accessibility of the documents}

The documents on the desktop may not have been equally accessible across conditions. In the $2 \mathrm{D}$ condition, all documents were equidistant from the scene virtual viewpoint and subtended the same visual angle as one another. In the 3D conditions, however, this was not the case. Due to the perspective view, documents from front to rear of the desktop were at various distances from the virtual viewpoint, and thus subtended various visual angles. More importantly, the linear perspective in the 3D conditions was more exaggerated than would be observed on a regular desktop. In fact, the perspective resembled that of a city block rather than a desktop. This exaggeration was not intentional, but rather a characteristic of the software used to display the scene. Documents toward the back of the desktop may have been less accessible than documents toward the front of the desktop.

Many participants in both the 3D dynamic and 3D Static conditions began creating their piles toward the back of the desktop, working their way forward. Further, some documents became hidden and completely obscured by closer documents when the participant had finished placing all of the documents on the desktop. Thus, during the retrieval session, the participant could not have possibly selected those hidden documents, if they so desired. This could have lowered performance. Discussions with participants afterward revealed that selecting the documents in the rear was quite difficult and that a number of participants in the 3D subjective conditions wanted to select one or more documents that they realized were completely obscured. The piles used for the fixed condition did not result in any hidden documents.

The difficulty in selecting documents in the 3D conditions might manifest itself as a 
higher number of attempts required to locate a document. That analysis did, in fact, show that the $2 \mathrm{D}$ condition required fewer attempts than either of the 3D conditions, which suggests documents could be less accessible in the 3D conditions. However, the analyses are not conclusive. The number of attempts is highly correlated with accuracy, $r(59)=.745$, and therefore, the significant effects for number of attempts could be due to factors other than document accessibility. To circumvent this confound, the effect of precise document distance (from the virtual viewpoint) on number of attempts was explored for the 3D conditions only. Hypothesizing that increased document distance lowers accessibility, the number of attempts should be expected to increase as the document distance increases. A linear regression of only the 3D conditions showed that the document distance significantly predicted the number of attempts required to locate that document, $F(1,1037)=8.118, p<.05, R^{2}=.08$. This illustrates that piles toward the rear of the desktop required more attempts to locate a particular document.

\section{D Display Technology}

Currently available 3D flat panel displays produce certain degradations and geometric distortions in the displayed scenes. In addition, the amount of degradation occurs differentially with the depth of objects in the scene. For example, as objects get farther away from the scene's center of projection they appear visually more compressed than in an actual scene. (Yeh \& Silverstein, 1992). Thus, the overall visual appearance of a 3D display deviates somewhat from users' expectations. This introduces potential ambiguity into users' understanding of spatial relationships in the display. To worsen matters, our perception and understanding of spatial objects in the real world is subject to ambiguity and inaccurate perceptual hypotheses (Gregory, 1977; Rock, 1983). Three-dimensional display technology 
would never be able to overcome this type of bias.

Since the 3D conditions of the present study were displayed on a flat-panel display, they did not use all of the cues to depth available in the real world. Although, many perceptual cues were indeed present (e.g., the visual cues of linear perspective, height in plane, relative size, and occlusion), other cues that may help us remember the locations of objects in the real world were not present (e.g., stereopsis). While vision seems to be the dominant spatial modality (Fisher, 1960; Over, 1966; Simpson, 1972), other modalities such as audition, touch, and proprioreception are constantly working in tandem to communicate spatial information to us in the real world (Welch \& Warren, 1986).

Egocentric localization refers to the ability to perceive the direction and distance of objects relative to the observer and is accomplished by the simultaneous efforts of vision, audition, touch, and proprioreception (Welch \& Warren, 1986). Thus, a composite memory of multiple sensory experiences (i.e., head and arm movements) may help us recall the location of an object. For example, orienting our bodies relative to objects such as furniture in a particular room may help all of our senses jointly "remember" object locations, which could be more powerful than relying on any one sense alone. When attempting to locate an item such as a journal article in our office, we might stand in our office and try to remember where or how we were standing when we put down the article. We may even mentally retrace our physical sequence of actions ('Let's see, I came into the office, checked e-mail here, then got something out of the filing cabinet, then I. . . ahhh here it is, on top of the filing cabinet!"). This kind of memory calls upon many senses and cannot be used on visually oriented 3D flat panel displays. 


\section{Top Document Visual Cues}

The appearance of the documents on the desktop may have provided unintentional cues to participants during retrieval. If the topmost document of a given pile was a target document during retrieval, very high accuracy and response time would be expected, since participants could use visual pattem matching. Using this unintended visual cue when attempting to find the documents could have been a confound and suggests the possibility that participants were not relying on relative spatial arrangements.

To examine whether accuracy for topmost documents was higher than for other documents, a 2 organization (subjective, fixed) $x 3$ cues (2D, 3D Static, 3D Dynamic) $x 2$ Document Position (Topmost, Non-Topmost) ANOVA was performed using accuracy as the dependent variable. The factors of organization and cues were analyzed between subjects and the factor of document position was analyzed within subjects. Document position was included in the full ANOVA model, as opposed to being analyzed independently, in order to assess both its main effects and its differential effects across the other factors. This ANOVA showed no significant main effect of document position on accuracy, $F(1,54)=0.998, p>$ .05 , nor any significant interaction effects involving document position.

Even though it is unclear exactly how many participants relied on this visual cueing strategy when searching for the documents, the analysis shows that the accuracy of topmost documents was not significantly different from that of other documents. So, topmost documents, although easily matched to the target document during retrieval through simple visual matching cues, did not elicit more accurate responses. It should be noted, however, that relatively few retrieval documents were topmost in the piles. So, the sample of documents used to obtain the mean accuracy of topmost documents was much less than for other 
documents.

In addition to possible confounds of target documents that are topmost in a pile, there is also the possibility that the topmost documents triggered the actual theme of the pile. A few participants actually stated that they examined the topmost document to try to remember the pile contents. To what degree this affected the current data remains unclear. Some of the findings, however, may shed light on this issue.

In the 3D conditions, the piles toward the back of the desktop subtend a smaller visual angle than those toward the front. Thus, the topmost documents toward the back of the desktop are much more difficult to discem. If the visual appearance of the topmost documents are in fact triggering memory for the pile theme, then retrieval documents placed toward the front of the desktop (in any location within a pile) should reliably produce better performance in the $3 \mathrm{D}$ conditions. In the $2 \mathrm{D}$ condition, all topmost documents were of equivalent distances from the scene virtual viewpoint and subtended like visual angles. Each topmost document in $2 \mathrm{D}$ could be expected to provide similar visual cues.

To explore this issue, a regression was performed in which the 3D desktop front to rear document distance from the scene virtual viewpoint was used to predict the first attempt accuracy for that document. This test might give a good indication of the role that topmost documents played in triggering the pile theme. The results showed that for the $3 \mathrm{D}$ conditions combined, document distance was a significant predictor of accuracy, $F(1,1037)=16.299, p$ $<.05, R^{2}=.015$. Documents at greater distances from the scene virtual viewpoint generally elicited lower accuracy. This result lends support to the hypothesis that top document visual cues were indeed acting as a trigger for the theme of the pile, although the total variance accounted for by document distance is rather small. Results for the 2D condition revealed that 
document distance did not significantly predict accuracy.

It is important to reiterate a few points about the 3D conditions. Some retrieval documents toward the back of the desktop were hidden by other closer documents which could in itself lower accuracy even though only first attempt vector lengths were used. Also, documents farther from the virtual viewpoint were relatively more difficult to select with the computer mouse, as a previously discussed analysis showed that document viewing position predicted number of attempts. These facts could have contributed in part to results above.

\section{Perceptual Cues on 2D Desktop}

As mentioned in the Introduction section, the 2D desktop in the present study was not completely void of perceptual cues. In particular, the depth cue of occlusion was included because that cue is available on all standard 2D desktop interfaces, and was necessary for consistency of response across desktop conditions in the retrieval session. Thus, the 2D desktop did not truly test performance under conditions of no perceptual cues. Even so, the desktops of the present study did reveal the effect of adding perceptual cues to an information space.

\section{Other Predictors of Performance}

In addition to the independent variables tested in the present study, some other variables measured proved to be relatively good predictors of retrieval accuracy. These variables were not involved in the hypotheses, but their predictive power warrants mention here. SOCI

A linear regression was performed on the current data to predict overall retrieval accuracy of a document from the SOCI of the document. This regression was significant, $F(1$, $24)=13.732, p<.05, R^{2}=.364$, showing that the SOCI of a document, calculated from the 
organization data, is a good predictor of later retrieval performance. A higher SOCI, representing a greater degree of categorizability, is generally associated with higher accuracy.

\section{Pile Agreement}

The degree to which a particular person's pile arrangement agreed with the document grouping frequencies in the overall proximity matrix was also shown to significantly predict individual accuracy for the subjective organization condition, $F(1,28)=4.177, p=.050, R^{2}=$ .130. This level of agreement was represented as a scalar index assigned to each participant, calculated from their arrangement of piles on the desktop. The more an individual's pile arrangement agreed with values in the overall proximity matrix, the better their accuracy in locating the documents during retrieval.

\section{Time On Task During Organization}

The amount of time spent organizing/viewing documents during the organization session significantly predicted mean first attempt vector length during retrieval, $F(1,54)=12.442, p<$ $.05, R^{2}=.187$. This analysis showed that the more time a participant spent on the overall organization session, the higher their accuracy tended to be. This was not due to any of the independent variables of the present study, since as mentioned previously, no differences were found for time on task for any of the experimental effects.

\section{Implications for Design of Information Workspaces}

The greatest benefit to document retrieval observed in the present study occurred when users were allowed to construct their own information structures. In fact, the effect of subjective organization was so strong that it overshadowed any contributory effects of perceptual cues. This is in contrast to the fixed organization scheme which elicited much worse performance and proved to be much more sensitive to the addition of perceptual cues. 
When the task allows, designers should give each user the ability to structure the information space in a way that is meaningful to him or her. As mentioned above, information storage/retrieval tasks in which a given user may interact with the information only once would not be conducive to subjective organization. An example of this type of task is a technical support web site for a computer product. A user may need help in configuring the product, may visit the product's technical support web site to get the needed information, and most likely never return to the site. But for tasks in which the user will most likely organize and maintain an information set over time, such as personal information portals or reference web sites, subjective organization appears to offer a great benefit.

If users must interact with a preconstructed, or fixed, information space, then using a 2D type of display will most likely result in the best retrieval performance. The addition of perceptual cues in fixed information spaces seems to degrade performance.

In general, the findings of the present study do not support using 3D flat panel displays for information spaces, whether static or dynamic in nature. Specifically, perceptual cues in flat panel displays may introduce confusing characteristics to the display and also a perception of increased complexity. Current 3D display technology, although convincing to our eyes, still produces perceptual distortions. Further, 3D scenes displayed on a flat panel are likely to produce distortions regardless of the level of technology. A 2D display would minimize the biases that occur in both real world and virtual 3D scenes and 2D may be a better fit for how users conceptualize, or at least work with information workspaces. From a practical standpoint, the development costs for a 2D interface would be less than for a 3D interface and the results of the present study show that the cost savings of a $2 \mathrm{D}$ interface would also promote better performance.

The 2D advantage is almost certainly task specific. Thus, when choosing between 2D 
and 3D displays, the costs and benefits of each must be weighed against the type of task for which the display will be used. People may conceptualize the organization of their information in two-dimensional or in descriptive/symbolic ways. Thus, 3D schemes may not provided a good fit for how they encode spatial information. Two-dimensional displays faithfully represent space and minimize distortions created by combining dimensions. However, other types of tasks have shown a clear superiority of 3D displays. These tasks include shape understanding/recognition (i.e., Humphrey \& Jolicoeur, 1993; St. John, Cowen, Smallman, \& Oonk, 2001), terrain matching (i.e., Hickox \& Wickens, 1999), and flight control and predictions of flight paths. Thus, these results do not contradict previous research that has shown benefits of 3D displays for specific types of tasks.

Further research should examine more closely the potential benefit for 2D information spaces and also explore users' mental models of these spaces. Preconstructed environments should be studied moreso than subjective ones, since subjectively organized spaces are highly beneficial regardless of perceptual cues present.

There is one compelling possibility that needs to be tested further: that people do not necessarily encode spatial information (i.e., objects on a desktop or in a room, the layout of a building) as a functional analog in order to later recall relative spatial locations. Even when spatial information is presented to people in a realistic 3D manner on a display for example, and they know they will have to recall the spatial locations of objects, perhaps a 3D display is not the best fit for how most people naturally encode the information. This was also discussed above. For large spaces especially, people must by necessity simplify the spatial information due to constraints of memory. Research has shown systematic distortions in how people encode relative spatial information. This simplification process most likely transforms the 
spatial environment not simply into an impoverished analog of the scene, but rather into more abstract, symbolic, or descriptive terms.

An interesting follow-up to the current research would be to examine whether a 2D arrangement shows an advantage during recall even if the organization was performed with a 3D arrangement. This would help to distinguish between the advantages of a) encoding and retrieval from the same type of information space, and b) retrieval from a simpler, more abstract information space regardless of the type of space used for encoding. If people are generally encoding the spatial information in nonspatial ways, then $2 \mathrm{D}$, due to its simpler more abstract layout, might be expected to show an overall advantage. 


\section{REFERENCES}

Abrams, D. (1997). Human factors of personal web information spaces, Unpublished master's thesis, University of Toronto, Ontario, Canada. Retrieved March 1, 1998 from http://virtual.inesc.pt/rct/rct.51.html.

Anstis, S. M. (1970). Phi movement as a subtraction process. Vision Research, 10, 1411-1430.

Baird, J. C., Wagner, M., \& Noma, E. (1982). Impossible cognitive spaces. Geographic Analysis, 14, 204-216.

Billingsley, P. A. (1982). Navigation through hierarchical menu structures: Does it help to have a map? In Proceedings of the $26^{\text {th }}$ Annual Meeting of the Human Factors and Ergonomics Society (pp. 103-107). Santa Monica, CA: Human Factors and Ergonomics Society.

Braddick, O. J. (1974). A short range process in apparent motion. Vision Research, 14, 519 527.

Braunstein, M. L. (1962). Depth perception in rotating dot patterns: Effects of numerosity and perspective. Journal of Experimental Psychology, 64, 415-420.

Braunstein, M. L. (1976). Depth perception through motion. New York: Academic.

Bush, V. (1945). As we may think. Atlantic Monthly, 176, 101-108.

Caelli, T. (1982). On discriminating visual textures and images. Perception and Psychophysics, 31, 149-159.

Card, S. K., Robertson, G. G, \& Mackinlay, J. D. (1991). The information visualizer: An information workspace. In Proceedings of Conference on Human Factors in Computing Systems (CHI '91) (pp. 181-188). New York: ACM.

Carswell, C. M., \& Wickens, C. D. (1987). Information integration and the object display: An interaction of task demands and display superiority. Ergonomics, 30, 511-527.

Chase, W. G., \& Ericsson, K. A. (1981). Skilled memory. In J. R. Anderson (Ed.), Cognitive skills and their acquisition (pp. 141-189). Hillsdale, NJ: Lawrence Erlbaum Associates.

Chase, W. G. (1978). Elementary information processes. In W. J. Estes (Ed.), Handbook of learning and cognitive processes (pp. 19-90). Hillsdale, NJ: Lawrence Erlbaum Associates.

Chase, W. G. (1986). Visual information processing. In K. R. Boff, L. Kaufman, \& J. P. 
Thomas (Eds.), Handbook of perception and human performance (pp. 28-1 - 28-71). New York: John Wiley and Sons.

Cole, D. I. (1982). Human aspects of office filing: Implications for the electronic office. In Proceedings of the $26^{\text {th }}$ Annual Meeting of the Human Factors Society (pp. 59-63). Santa Monica, CA: Human Factors and Ergonomics Society.

Darken, R. P., \& Sibert, J. L. (1993). A toolset for navigation in virtual environments. In Proceedings of ACM Conference on User Interface Software \& Technology (UIST '93) (pp. 157-165). New York: ACM.

Darken, R. P., and Sibert, J. L. (1996). Wayfinding strategies and behaviors in large virtual worlds, In Proceedings of Conference on Human Factors in Computing Systems (CHI '96) (pp. 142-149). New York: ACM.

Elvins, T. T., Nadeau, D. R., Schul, R., \& Kirsh, D. (1998). Worldlets: 3D thumbnails for 3D browsing. In Proceedings of Conference on Human Factors in Computing Systems (CHI '98) (pp. 163-170). New York: ACM.

Fertig, S., Freeman, E. \& Gelernter, E. (1996). Lifestreams: An alternative to the desktop metaphor. In Proceedings of Conference on Human Factors in Computing Systems (CHI '96) (pp. 410-4l1). New York: ACM.

Fisher, G. H. (1960). Intersensory localisation in three modalities. Bulletin of the British Psychological Society, 41, 24-25A.

Forsythe, C., Grose, E. \& Ratner J. (1998). Human factors and web development. Mahwah, NJ: Lawrence Erlbaum Associates.

Foster, D. H. (1971). A model of the human visual system in its response to certain classes of moving stimuli. Kybernetik, 8, 69-84.

Foster, R. W. (1996, October). The internet: A perspective for internetworking. Inside DPMA, 1, 3.

Gibson, J. J. (1950). Perception of the visual world. Boston: Houghton Mifflin.

Graham, M., \& Rogers, B. (1982). Interactions between monocular and binocular depth aftereffect. Investigative Ophthalmology and Visual Science, 22 (Suppl.), 272.

Gregory, R. L. (1977). Eye and brain. London: Weidenfeld \& Nicolson.

Hammond, N., \& Allinson, L. (1987). The travel metaphor as design principle and training aid for navigating around complex systems. In Proceedings of the $\mathrm{HCI}$ 87, 75-90.

Cambridge, MA: Cambridge University Press. 
Hewins, E. T. (1990). Information need and use studies. Annual Review of Information Science and Technology, 25, 145-172.

Hickox, J. G., \& Wickens, C. D. (1999). Effects of elevation angle disparity, complexity, and feature type on relating out-of-cockpit field of view to an electronic cartographic map. Journal of Experimental Psychology: Applied, 5, 284-301.

Howard, J. H., \& Kerst, S. M. (1981). Memory and perception of cartographic information for familiar and unfamiliar environments. Human Factors, 23, 495-503.

Humphrey, K., \& Jolicoeur, P. (1993). An examination of the effects of axis foreshortening, monocular depth cues, and visual field on object identification. Quarterly Journal of Experimental Psychology, 46A, 137-159.

Hutchins, E. L., Hollan, J. D., \& Norman, D. A. (1985). Direct manipulation interfaces. Human-Computer Interaction, 1, 311-338.

Inder, R., \& Stader, J. (1994). Bags and viewers: A metaphor for structuring a database browser. In Proceedings of Advanced Visual Interfaces '94 (pp. 228-230). New York: ACM.

Jacob, R. J. K. (1989). Direct manipulation in the intelligent interface. In P. A. Hancock \& M. H. Chignell (Eds.), Intelligent interfaces: Theory, research, and design (pp. 165-212). Amsterdam: Elsevier Science Publishers B. V.

Jones, W. P., \& Dumais, S. T. (1986). The spatial metaphor for user interfaces: Experimental tests of reference by location versus name. ACM Transactions on Office Information Systems, 4, 42-63.

Kosslyn, S. M. (1980). Image and mind. Cambridge, MA: Harvard University Press.

Kosslyn, S. M., Pick, H. L., \& Fariello, G. R. (1974). Cognitive maps in children and men. Child Development, 45, 707-716.

Lucas, P., \& Schneider, L. (1994). Workscape: A scriptable document management environment. In Proceedings of Conference on Human Factors in Computing Systems (CHI '94; Companion) (pp. 9-10). New York: ACM.

Lynch, K. (1960). The image of the city. The MIT Press: London.

Malone, T. W. (1983). How do people organize their desks? Implications for the design of office information systems. ACM Transactions of Office Information Systems, 1, 99-112.

Mander, R, Salomon, G., \& Wong, Y.Y. (1992). A 'pile' metaphor for supporting casual organization of information. In Proceedings of Conference on Human Factors in 
Computing Systems (CHI '92) (pp. 627-634). New York: ACM.

Mandler, J. M., Seegmiller, D., \& Day, J. (1977). On the encoding of spatial information. Memory and Cognition, 5, 10-16.

Mayhew, D. (1998). Introduction. In C. Forsythe, E. Grose, \& J. Ratner (Eds.), Human factors and web development (pp. 1-13). Mahwah, NJ: Lawrence Erlbaum Associates.

Moar, I., \& Bower, G. H. (1983). Inconsistency in spatial knowledge. Memory and Cognition, $11,107-113$.

Neale, D. C., \& Caroll, J. M. (1997). The role of metaphors in user interface design. In M. G. Helander, T. K. Landauer, \& P. V. Prabhu (Eds.), Handbook of human-computer interaction (pp. 441-462). Amsterdam: Elsevier Science Publishers B. V.

Newcombe, N., \& Liben, L. S. (1982). Barrier effects in the cognitive maps of children and adults. Journal of Experimental Child Psychology, 34, 46-58.

Over, R. (1966). An experimentally induced conflict between vision and proprioreception. British Journal of Psychology, 57, 335-341.

Park, S. A., \& Woldstad, J. C. (2000). Multiple two-dimensional displays as an alternative to three-dimensional displays in telerobotic tasks, Human Factors, 42, 592-603.

Pejtersen, A. M., \& Nielsen, F. (1991). Iconic interface for interactive fiction retreival in libraries based on a cognitive task analysis. In H. J. Bullinger (Ed.), Human aspects in computing: Design and use of interactive systems and work with terminals (pp. 753762). Amsterdam: Elsevier Science Publishers, B. V.

Peters, R. D., Yastrop, G. T., \& Boehm-Davis, D. A. (1988). Predicting information retrieval performance. In Proceedings of the $32^{\text {nd }}$ Annual Meeting of the Human Factors Society (pp. 301-305). Santa Monica, CA: Human Factors and Ergonomics Society.

Peterson, M. J. (1975). The retention of imagined and seen spatial matrices. Cognitive Psychology, 7, 181-193.

Philip B. R., \& Fisichelli, V. R. (1945). Effect of speed of rotation and complexity of pattem on the reversals of apparent movement in Lissajous figures. American Journal of Psychology, 58, 530-539.

Pinker, S., \& Kosslyn, S. M. (1978). The representation and manipulation of threedimensional space in mental images. Journal of Mental Imagery, 2, 69-84.

Poblete, F. (1995). The use of information visualization to enhance awareness of hierarchical structure. Unpublished master's thesis, University of Toronto, Ontario, Canada. 
Poggio, T., Reichardt, W., \& Hausen, K. (1983). Figure-ground discrimination by relative movement in the visual system of the fly. Biological Cybernetics, 46,1 .

Regen, D. M., Kaufman, L., \& Lincoln, J. (1986). Motion in depth and visual acceleration. In K. R. Boff, L. Kaufman, \& J. P. Thomas (Eds.), Handbook of perception and human performance (pp.19-1 - 19-45). New York: John Wiley and Sons.

Regen, D. M., \& Spekreijse, H. (1970). Electrophysiologcial correlate of binocular depth perception in man. Nature, 255, 92-94.

Reichardt, W., \& Poggio, T. (1979). Figure-ground discrimination by relative movement in the visual system of the fly. Biological Cybernetics, 35, 81-100.

Robertson, G., Czerwinski, M., Larson, K, Robbins, D. C., Thiel, D. \& van Dantzich, M. (1998). Data mountain: Using spatial memory for document management. In Proceedings of Conference on User Interface Software \& Technology (UIST '98) (pp. 153-162). New York: ACM.

Rock, I. (1983). The logic of perception. Cambridge, MA: MIT Press.

Rogers, B., \& Graham, M. (1982). Horizontal-vertical anisotropies in the perception of 3-D depth surfaces. Investigative Ophthalmology and Visual Science, 22, (Suppl.) (p. 273).

Ruddle, R. A., Payne, S. J., \& Jones, D. M. (1997). Navigating buildings in "desk-top" virtual environments: Experimental investigations using extended navigational experience. Journal of Experimental Psychology: Applied, 3, 143-159.

Schneiderman, B. (1987). Designing the user interface: Strategies for effective humancomputer interaction, $2^{\text {md }}$ edition. Reading, MA: Addison-Wesley.

Schneiderman, B. (1998). Designing the user interface: Strategies for effective humancomputer interaction, $3^{\text {rd }}$ edition. Reading, MA: Addison-Wesley.

Shafrir, E., \& Nabkel, J. (1994). Visual access to hyper-information: Using multiple metaphors with graphic affordances. In Proceedings of Conference on Human Factors in Computing Systems (CHI'94; Companion) (p. 142). New York: ACM.

Simpson, W. E. (1972). Latency of locating lights and sounds. Journal of Experimental Psychology, 93, 169-175.

Smith, S. (1981). Exploring compatibility with words and pictures. Human Factors, 23, 305316.

Stevens, A., \& Coupe, P. (1978) . Distortions in judged spatial relations. Cognitive Psychology, 10, 422-437. 
St. John, M., Cowen, M. B., Smallman, H. S., \& Oonk, H. M. (2001). The use of 2D and 3D displays for shape understanding versus relative position tasks. Human Factors, 43, 7998.

Tversky, B. (1981). Distortions in memory for maps. Cognitive Psychology, 13, 407-433.

Ullman, S. (1979). The interpretation of visual motion. Cambridge, MA: MIT Press.

Vaananen, K. (1993). Multimedia environments: Supporting authors and users with real-world metaphors. In Proceedings of ACM INTERCHI'93 Conference on Human Factors in Computing Systems (Adjunct) (pp. 99-100). New York: ACM.

Vicente, K. J., Hayes, B. C., \& Williges, R. C. (1987). Assaying and isolating individual differences in searching a hierarchical file system. Human Factors, 29, 349-359.

Waterworth, J. A., \& Chignell, M. H. (1997). Multimedia interaction. In M. G. Helander, T. K. Landauer, \& P. V. Prabhu (Eds.), Handbook of human-computer interaction (pp. 915946). Amsterdam: Elsevier Science Publishers B. V.

Weber, C. O. (1930). Apparent movement in Lissajous figures. American Journal of Psychology, 42, 647-649.

Welch, R. B., \& Warren, D. H. (1986). Intersensory interactions. In K. R. Boff, L. Kaufman, and J. P. Thomas (Eds.), Handbook of perception and human performance (pp. 25-1 25-36). New York: John Wiley and Sons.

Westerman, S. J. (1998). A comparison of the cognitive demands of navigating two- versus three-dimensional spatial database layouts. Ergonomics, 41, 207-212.

White, B. W., \& Mueser, G. E. (1960). Accuracy in reconstructing the arrangement of elements generating kinetic depth displays. Journal of Experimental Psychology, 60, 111.

Wickens, C. D (1992). Engineering psychology and human performance, $2^{\text {nd }}$ edition. New York: Harper Collins.

Wickens, C. D., \& Seidler, K. S. (1995). Information access and usability. In R. S. Nickerson (Ed.), Emerging needs and opportunities for human factors research (pp. 200-219). Washington, DC: National Academy Press.

Witmer, B. G., Bailey, J. H., Knerr, B. W., \& Parsons K. C. (1996). Virtual spaces and real world places: Transfer of route knowledge. International Journal of Human-Computer Studies, 45, 413-428.

Witmer, B. G., \& Singer, M. J. (1994). Measuring presence in virtual environments (ARI 
technical report 1014). Alexandria, VA: U. S. Army Research Institute for the Behavioral and Social Sciences.

Woods, D. D., Roth, E. M., Stubler, W. F., \& Mumaw, R. J. (1990). Navigating through large display networks in dynamic control applications. In Proceedings of the $34^{\text {th }}$ Annual Meeting of the Human Factors Society (pp. 396-399). Santa Monica, CA: Human Factors and Ergonomics Society.

Yates, F. A. (1966). The art of memory. Chicago: The University of Chicago Press.

Yeh, Y., \& Silverstein, L. D. (1992). Spatial judgements with monoscopic and stereoscopic presentation of perspective displays. Human Factors, 34, 583-600. 


\section{APPENDIX A \\ DOCUMENT ID NUMBERS AND TITLES}

ID

Title

\section{Acting Workshop On-line (AWOL)}

ACTING-PRO, discussion list for professional actors and directors

LA Actors Online Home Page

Los Angeles Fight Academy

The Academy of the Sword: Historical Swordfighting and Theatrical Swashbuckling. The Society of American Fight Directors

American Theater Web - Find theaters, Broadway shows, and musicals

CHILDREN'S THEATRE WORKSHOP - TOLEDO, OHIO

Standards

The Philadelphia Young Playwrights Festival

The Drama teacher's Resource Room

The Internet Theatre Database

Airline tickets, hotels, cars, vacations: Go Virtually Anywhere with Travelocity.com Fool.com: Finance and Folly Ñ Main Page

Quicken.com

CIBER

Welcome to the Group of Thirty

Joint BIS-IMF-OECD-World Bank statistics on extemal debt

Understanding the Global Economy by Howard Richards

All About The Intemet - A weekly column for Internet beginners by Konrad Roeder Site Seeing On the Internet

The Complete Internet Guide and Web Tutorial

FixWindows.com - The Windows Troubleshooting Site

Microsoft Windows Me - Home

EURYDICE - The Information Network on Education in Europe - Homepage

Kids Can Make A Difference - Home Page

SchoolWorld/Homepage

State of American Education

Eschatology, The Walter Method

feminist educational research

WGSt - Feminist Pedagogy and the Integration of Knowledge

Teaching History $\overline{\mathrm{N}}$ A Journal of Methods

Hollywood.com - MovieTalk

Ralph Meeker: Collections of the Meeker Museum

The Actress Archives

Dilbert: Propaganda for New-Order Bolshevism

TV Guide Oniine

Universal Studios

Welcome to E! Online

C Y B ER CRIME

cyberlaw.com

United Nations News Centre

The Center for Democracy - Index

The National Democratic Institute for International Affairs

Welcome to ICS Press

Political Resources on the Net

Department of Education: Office of the Under Secretary 
ED/Office for Civil Rights (OCR)

National Education Goals Panel

U.S. Department of Education (ED) Home Page

Los Angeles Times

Politically Inconrect

Better Homes \& Garden How-To Encyclopedia: home repair / remodeling / landscaping Home Ideas: Home Improvement Ideas for Kitchen, Bath, Yard and Garden, etc.

Welcome to AmericanHomeStyle.com

Flight Arrivals \& Departures

Flight Progress.com

Farebeater - The Fastest Way To The Lowest Fares

tiss.com - Cheapest Flights Around The World

Yahoo Travel: Roundrip Flight Search

Travel Source

TRAVELCOM

Welcome to Travel City

Kapili.com:Biology4Kids! Your Biology Web site!

ARCHAEOLOGY WORLD

Ant History Network Home Page

Welcome to the Archaeological Adventure

The 5th Student Research Conference on Gender: Radford University

TOPSS Homepage

Welcome to psychology.com

Center For Feminist Research

National Council for Research on Women

Digital Clubhouse Network

Resource Center for Cyberculture Studies

Plugged In: Women and Technology with Soledad O'Brien 


\section{APPENDIX B \\ ORGANIZATION SESSION INSTRUCTIONS, SUBJECTIVE CONDITION}

For this study, you will view 75 web documents on the computer that cover many different topics.

Your task is to look at each document as it is presented to you on the right half of the screen and decide what each document is about. Based on that, you should create different piles of documents on the desktop on the left half of the screen, just as you might have piles of papers on your own desk that represent different kinds of information.

For example, on a desk in your room, you might have piles that represent different things such as bills, school stuff, or coupons. You might even have a "miscellaneous" pile for items that you can't quite fit into pile.

(Show Test run view)

To place a document on the desktop or on an existing pile on the desktop, simply SINGLE CLICK in the desired location. DO NOT DOUBLE CLICK.

The place on the desktop that you click will become the center of the document. For example, if you want to begin a new pile on the desktop, click on the desktop at the location of your choice. The document will appear there.

If you want to place a document in an existing pile of other documents, click on the topmost document of the pile.

You can't move a document once you place it on the desktop, so if you place a document and don't like where you put it, please just keep going.

(Instructions on viewing thumbnails using 'Ctrl' key)

During this task, you can create as many piles as you like, place as many documents in each pile as you like, and place the piles anywhere on the desktop provided all of the piles can fit on the desktop and no two piles overlap each other. You will aiso have as much time as you like.

Remember, try not to create piles that overlap each other, and try to keep all of your piles completely on the desktop.

There is not a right or wrong way to complete this task, there is simply your way.

In the second part of the experiment, you will be asked to specify the location of certain documents in your piles, so create your piles in a way that works best for you.

Work quickly, but slow enough to become familiar with the documents and the document locations.

The task will inform you when you are done, so keep working until it tells you that you are finished. 


\section{APPENDIX C \\ ORGANIZATION SESSION INSTRUCTIONS, FLXED CONDITION}

For this study, you will view 75 documents from the Internet that cover many different topics.

Your task is to look at each document as it is presented to you on the right half of the screen and decide what each document is about. Based on that, you should become familiar with the location of the document on the desktop on the left half of the screen. The desktop contains piles of web documents that represent various kinds of things.

For example, on a desk in your room, you might have piles that represent different things such as bills, school stuff, or coupons. You might even have a "miscellaneous" pile for items that you can't quite fit into pile.

(Show Test run view)

To move from one document to the next, click on the button "Next Document". The document will change and its location on the desktop will be highlighted. Try to become familiar with the document's location on the desktop, specifically which pile the document is in and where in the pile the document is, and perhaps the general theme of the pile it is in.

(Instructions on viewing thumbnails using 'Ctrl' key)

Remember, there is not a right or wrong way to complete this task, there is simply your way.

In the second part of the experiment, you will be asked to specify the location of certain documents in the piles, so keep that in mind as you look through the documents.

Work quickly, but slow enough to become familiar with the documents, and the theme of each pile.

The task will inform you when you are done, so keep working until it tells you that you are finished. 


\section{APPENDIX D \\ RETRIEVAL SESSION INSTRUCTIONS, SUBJECTIVE CONDITION}

During this part of the experiment, you will be asked to find some of the documents that you organized in the first part of the experiment. On the left half of the screen you will see the desktop and the piles of documents you created. Each document you are required to find will be on the right half of the screen. As each document is presented, make your best guess as to its location by SINGLE CLICKING on a document on the desktop. DO NOT DOUBLE CLICK! You will have ten attempts to find the document, after which you will have to move on to the next document. With each click/ attempt you will see text on the screen telling you if you clicked in the correct pile and/or if you are getting closer to the document. When you find the correct document, you will see the word "CORRECT DOCUMENT", and hear a sound indicating that you are right, and the document on the right will automatically change to the next one.

(demonstration of task)

If you do not find the correct document, don't worry. Simply keep trying to do your best. Just because you don't find the correct document doesn't mean you performed poorly.

You will have as much time as you need to complete this experiment, but try to find each document in the fewest number of attempts.

The task will inform you when you are done, so keep working until it indicates that you are finished. 


\section{APPENDIX E \\ RETRIEVAL SESSION INSTRUCTIONS, FIXED CONDITION}

During this part of the experiment, you will be asked to find some of the documents that you looked at in the first part of the experiment. On the left half of the screen you will see the desktop and the piles of documents you created. Each document you are required to find will be on the right half of the screen. As each document is presented, make your best guess as to its location by SINGLE CLICKING on a document on the desktop. DO NOT DOUBLE CLICK! You will have ten aitempts to find the document, after which you will have to move on to the next document. With each click/ attempt you will see text on the screen telling you if you clicked in the correct pile and/or if you are getting closer to the document. When you find the correct document, you will see the word "CORRECT DOCUMENT", and hear a sound indicating that you are right, and the document on the right will automatically change to the next one.

(demonstration of task)

If you do not find the correct document, don't worry. Simply keep trying to do your best. Just because you don't find the correct document doesn't mean you performed poorly.

You will have as much time as you need to complete this experiment, but try to find each document in the fewest number of attempts.

The task will inform you when you are done, so keep working until it indicates that you are finished. 
APPENDIX F

CLUSTER ANALYSIS DENDROGRAM FROM PILOT STUDY

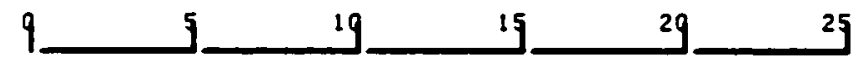

DOC 63

DOC 64

$D O C 14$

$D O C 61$

DOC 62

$D O C 59$

$D 0 C 60$

DOC 57

DOC 58

DOC 18

DOC 19

$D O C 15$

$D O C 16$

DOC 20

$D \propto C+3$

$D O 52$

$D O C 44$

DOC 45

$D O C 47$

$D O C 49$

$D O C+1$

$D O C+2$

$D O C 24$

$D O C 25$

$D \propto C 21$

DOC 23

$D O C 22$

DOC 74

$D \propto C 31$

$0 \propto 32$

$00 \mathrm{C} 72$

$D O C 73$

$D O C 69$

DOC 76

$D \propto 29$

$D \propto 51$

$D O C 48$

$D O C 33$

DOC 65

$D O C 26$

$D O C 50$

$D \propto 27$

DOC 17

DOC 70

$D O C 28$

DOC 30

DOC 66

$D O C 68$

$D \propto 67$

DOC 71

$D O C 75$

$D 0046$

DOC 55

$D \propto C 56$

DOC 54

DOC 5

$D \propto 7$

$D \propto C$ !

DOC 9

DOC 10

$D \propto C ~ 12$

$D \propto 11$

DOC 13

$D O C 3$

DOC 8

DOC 2

DOC 6

$00 C 39$

$D O C 40$

$D O C \quad 38$

DOC 34

DOC 36

$D O C 53$

$D O C 35$

DOC 37

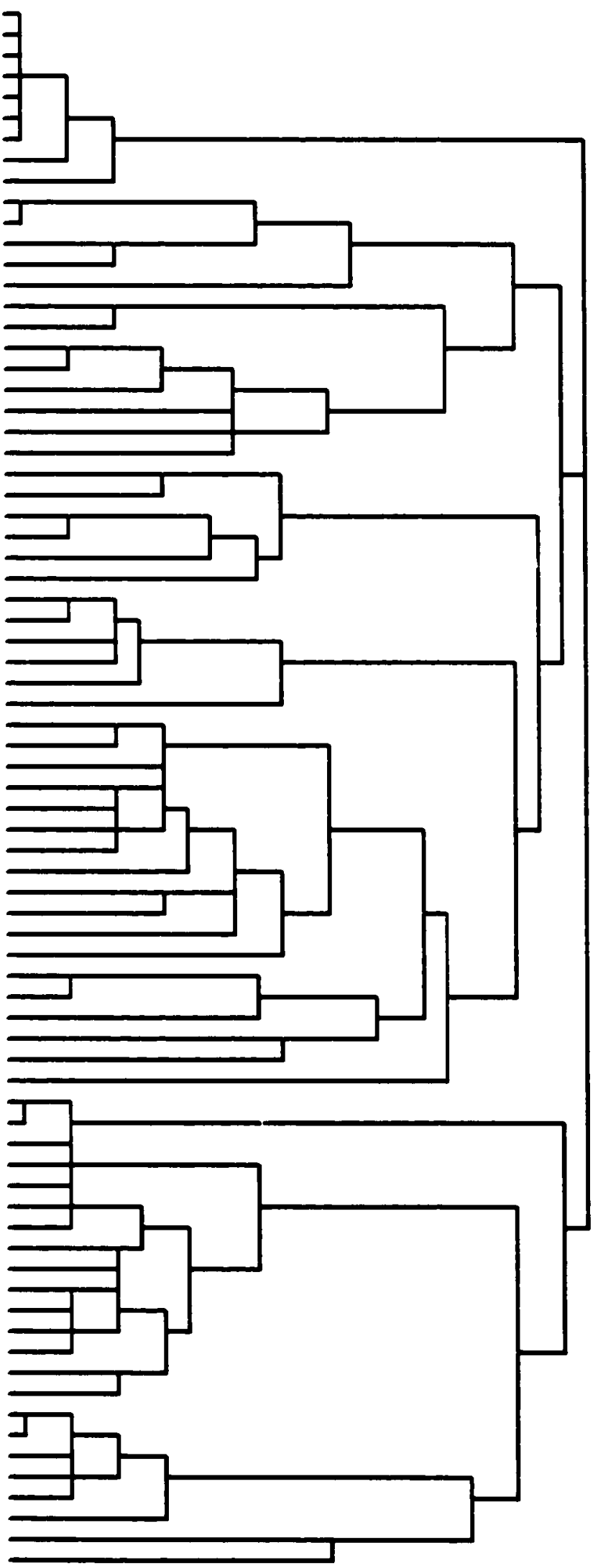


APPENDIX G

\section{CLUSTER ANALYSIS DENDROGRAM FROM PRESENT STUDY}
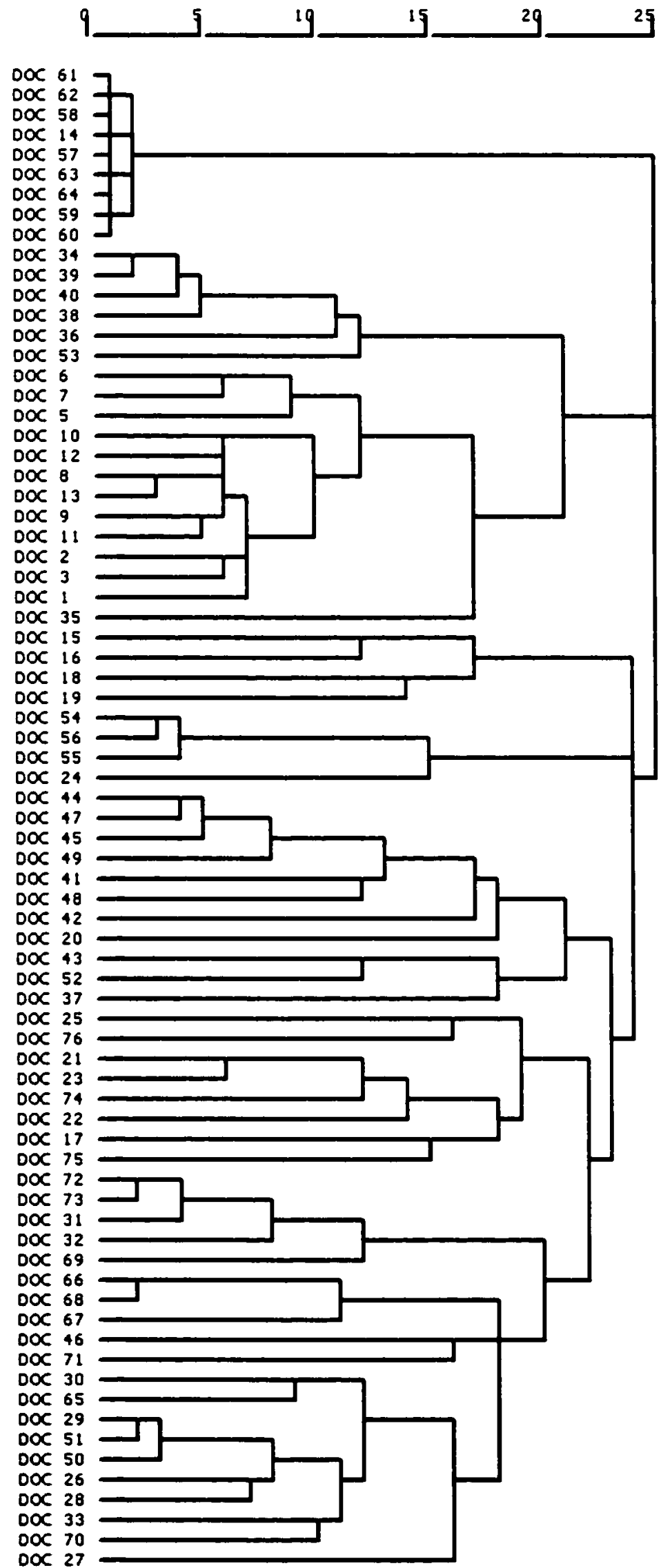


\section{VITA}

Todd M. Eischeid, the oldest of four siblings, was born in Dubuque, Iowa in 1968 and raised in Virginia. In June 1987, he graduated from Franklin High School in Franklin, Virginia; and in May 1992, graduated from Virginia Tech with a Bachelor of Science degree in Psychology. As well as for psychology, he had a passion for music and guitar, which he satisfied by playing in a band; he also placed 4 th in a rock guitar contest. From 1992-1994 he pursued a career in music, writing songs and playing electric guitar in a band.

In Fall 1995 he was admitted to the doctoral program in Industrial / Organizational Psychology at Old Dominion University, where he completed his master's thesis in 1997, specializing in Human Factors. His professional interests include human-computer interaction, and specifically alternative interface design. He currently resides in Williamsburg with his wonderful wife, Amy, to whom he was married on July 26, 1997.

Todd M. Eischeid may be contacted at:

Old Dominion University

Department of Psychology

Norfolk, VA 23529 